\title{
Dynamic Modelling of Induced Draft Cooling Towers With Parallel Heat Exchangers, Pumps and Cooling Water Network
}

\author{
J.H. Viljoen ${ }^{\mathrm{a}}$, C.J. Muller ${ }^{\mathrm{a}}$, I.K. Craig, ${ }^{\mathrm{a}, *}$ \\ ${ }^{a}$ Department of Electrical, Electronic, and Computer Engineering, University of Pretoria, \\ Pretoria, South Africa.
}

\begin{abstract}
In the process industries, cooling capacity is an important enabler for the facility to manufacture on specification product. The cooling water network is an important part of the over-all cooling system of the facility. In this paper a cooling water circuit consisting of 3 cooling towers in parallel, 2 cooling water pumps in parallel, and 11 heat exchangers in parallel, is modelled. The model developed is based on first principles and captures the dynamic, non-linear nature of the plant. The modelled plant is further complicated by continuous, as well as Boolean process variables, giving the model a hybrid nature. Energy consumption is included in the model as it is a very important parameter for plant operation. The model is fitted to real industry data by using a particle swarm optimisation approach. The model is suitable to be used for optimisation and control purposes.

Keywords: dynamic modelling, cooling tower, cooling water network, optimisation, particle swarm optimisation, hybrid systems
\end{abstract}

\section{Introduction}

Optimisation and process control studies of Cooling Water (CW) networks in the process industries are not common in the literature. One reason for

*Corresponding author. Tel.: +27 124202172.

Email addresses: henning@swissmail.org (J.H. Viljoen), nelismuller@gmail.com (C.J. Muller), ian.craig@up.ac.za (I.K. Craig)

Postprint submitted to Journal of Process Control

March 19, 2018 
this is the relative scarcity of dynamic models of such systems. Dynamic, first

5 principles modelling is done in this paper with the aim of using the resulting model in process control and optimisation studies.

Dynamic modelling has lately been applied by Muller and Craig [1] to cooling water networks with the view to optimise and control the entire process. In [1] a dual circuit cooling water network was modelled including power consumption, with high-level models for the cooling towers, and the plant exchangers. What distinguishes this paper from [1] is that a single circuit network is modelled with detailed heat and mass balance modelling of the internals of the 3 cooling towers, as well as individual models for the plant heat exchangers, and network hydraulics. In addition, in this paper variable speed drives are added to the modelling of the cooling tower fans and the CW pumps. For the purpose of optimisation, more detailed modelling of the process enables better root cause understanding of process conditions, and enables greater increases in efficiency in areas such as water loss and power consumption in the cooling water circuit. Another optimisation area enabled by deeper levels of modelling, is the ratio between the flow rates to the different parts of the plant as served by the different heat exchangers. For the purposes of control, more detailed modelling will add robustness to the closed loop system by decreasing the difference between the actual plant and the controller plant model during both steady-state and dynamic transient conditions, as well as add degrees of freedom to be used by 25 the controller.

A cooling water system is mathematically complex due to the interaction between the thermodynamics and hydraulics 2, 3. Mathematical modelling of a cooling water network has been done by various researchers. Neural network modelling of a cooling water circuit for a petro-chemical facility was done by 30 Malinowski et al. 4]. Multiple authors have done static hydraulic and static thermal modelling (see e.g. [2]).

Power consumption efficiency optimisation is an important strategic focus area in the process industry. The power requirements for cooling water networks have been calculated in [1] and [5]. It is also included in the modelling done in 


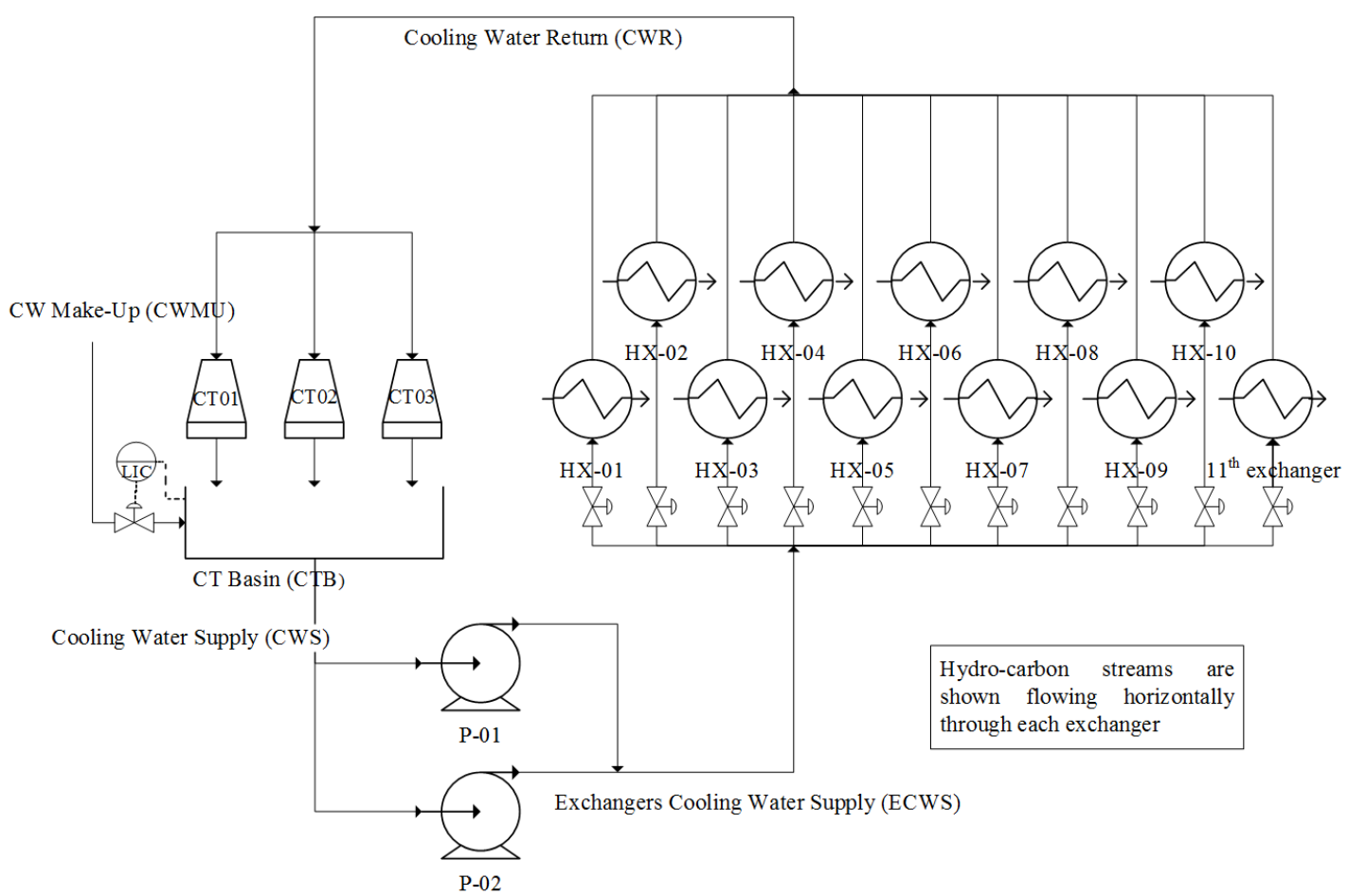

Figure 1: The cooling network and associated equipment

this paper.

The cooling water network modelled in this paper is inherently non-linear, as well as hybrid, since the pumps and cooling tower fans can be in a running state, or can be off. This gives the state of the equipment a Boolean nature. The system therefore has a combination of continuous process state variables, 40 as well as Boolean state variables. This has an effect on the power consumption modelling of the network, as well as the ultimate aim of control and optimisation. In order to optimise and control a hybrid non-linear system, techniques from the realm of Mixed Integer Non-linear Programming (MINLP) need to be used [6]. 


\section{Process Description}

The cooling water circuit modelled in this paper is graphically depicted in Figure 1. The cooling capacity is supplied by 3 Cooling Towers (CTs) in parallel. Cooling Water Return (CWR) is sprayed into each cooling tower at the top of the tower. At the bottom of the towers, the cooling water falls into a common Cooling Tower Basin (CTB). Airflow through the cooling towers is induced by induction motor driven fans at the top of the cooling towers.

Each tower is designed for a maximum cooling water flow rate of 8,700 $\mathrm{m}^{3} / \mathrm{h}$, a heat duty of $101 \mathrm{MW}$, cooling water return temperature of $45^{\circ} \mathrm{C}$, and a supply temperature of $35^{\circ} \mathrm{C}$. The wet bulb temperature is designed to be 31

${ }_{55}^{\circ} \mathrm{C}$. Evaporative losses from the cooling tower are designed to be $1.83 \%$ of the total cooling tower flow.

The cooling tower fans are $9.1 \mathrm{~m}$ in diameter, and rotate at a design speed of $120.1 \mathrm{rpm}$. The design power consumption of each fan is $137 \mathrm{~kW}$.

Each pump is designed for an operating flow rate of $3,850 \mathrm{~m}^{3} / \mathrm{h}$ and an 60 operating discharge pressure of 5.3 barg. Each pump was designed to run at an operating point of $740 \mathrm{rpm}$ at which it consumes $811 \mathrm{~kW}$. However, pumps on the actual plant consume more power than this design power operating point.

133 parallel cooling water heat exchangers are fed with cooling water by the cooling towers and the pumps. Most of the heat exchangers are used to cool down process hydro-carbon streams with the cooling water coming from the cooling water pumps. However, $73 \%$ of all the cooling water flows through the 10 biggest heat exchangers, and $27 \%$ flows through the remaining 123 smaller exchangers. After having passed through the 133 heat exchangers, the cooling water flows back to the cooling towers, completing the cooling water circuit.

70 The 123 smaller exchangers were combined into a single $11^{\text {th }}$ exchanger (see Section 5 for modelling purposes.

In the real plant this paper is based on, each heat exchanger has a hand valve upstream of it. In the model developed here, this hand valve is modelled as a control valve for simulation purposes and motiving future advanced control 
strategies.

\section{Model Derivation}

In this section the modelling work done is documented, with references to the literature, for each sub area of the model. Dynamic models for the major process unit operations (cooling towers, pumps, valves and heat exchangers) are derived separately, and the equations are developed to link the different operations.

\subsection{Cooling tower modelling}

The cooling tower model has been constructed with the following initial assumptions:

1. The cooling tower operates under adiabatic thermodynamic conditions.

2. The water and air streams are divided into 10 sections in the vertical dimension (see Figure 2). The water flow changes vertically between sections throughout the tower due to evaporation.

3. The density and specific heat of the water and dry air are constant accross the height of the cooling tower, since the change in temperatures are relatively small.

4. The fill packing is uniformly wet and in thermal equilibrium with the aqueous phase, and covers all 10 sections in the vertical dimension of the tower.

5. Water waste due to drifting is negligible. As per design this is $0.02 \%$ of the water flow through the tower. It is assumed zero for the purposes of this paper.

6. There is no meaningful delay between the tower, the pumps and the heat exchangers.

Kloppers and Kröger [7] did a comparison of 3 methods in the literature that are historically used to evaluate and model the steady-state behavior and 


\begin{tabular}{|c|c|c|c|}
\hline Symbol & Description & $\begin{array}{l}\text { Steady-state } \\
\text { value }\end{array}$ & Units \\
\hline$A$ & Heat exchanger heat exchange surface area & $\begin{array}{l}\text { Per ex- } \\
\text { changer }\end{array}$ & $\mathrm{m}^{2}$ \\
\hline$a_{c t}$ & $\begin{array}{l}\text { Contact area of water surface per volume unit in the } \\
\text { tower }\end{array}$ & 399.9 & $\mathrm{~m}^{2} / \mathrm{m}^{3}$ \\
\hline$a_{h}$ & Horizontal section area of cooling tower & 207.4 & $\mathrm{~m}^{2}$ \\
\hline$a_{p_{0}}$ & Pump hydraulic curve constant 0 & $4,514.46$ & $\mathrm{~Pa} \cdot \mathrm{s}^{2}$ \\
\hline$a_{p_{1}}$ & Pump hydraulic curve constant 1 & $1,926.25$ & $\mathrm{~Pa} \cdot \mathrm{s}^{2} / \mathrm{m}^{3}$ \\
\hline$a_{p_{2}}$ & Pump hydraulic curve constant 2 & $-45,255.62$ & $\mathrm{~Pa} \cdot \mathrm{s}^{2} / \mathrm{m}^{6}$ \\
\hline$a_{\text {seg }}$ & $\begin{array}{l}\text { The contact area of water surface per segment vol- } \\
\text { ume }\end{array}$ & 116,951 & $\mathrm{~m}^{2}$ \\
\hline$c_{a}$ & Heat capacity of air & $1,008.5$ & $\mathrm{~J} /(\mathrm{kg} \cdot \mathrm{K})$ \\
\hline$C_{v C V}$ & Control Valve valve $\mathrm{C}_{\mathrm{v}}$ coefficient & 0.0040572 & $\left.\mathrm{~m}^{3} /(\mathrm{s} \cdot \sqrt{P a})\right)$ \\
\hline$C_{v C T}$ & Cooling Tower water spray nozzel $\mathrm{C}_{\mathrm{v}}$ & 121.2 & $\left.\mathrm{~m}^{3} /(\mathrm{s} \cdot \sqrt{P a})\right)$ \\
\hline$c_{w}$ & Heat capacity of water & 4,185 & $\mathrm{~J} /(\mathrm{kg} \cdot \mathrm{K})$ \\
\hline$F$ & Mass flow rate & $\begin{array}{l}\text { Per equip- } \\
\text { ment }\end{array}$ & $\mathrm{kg} / \mathrm{s}$ \\
\hline$F_{a_{i n}}$ & Dry air flow rate into a cooling tower segment & Per segment & $\mathrm{kg} / \mathrm{s}$ \\
\hline$F_{a_{\text {out }}}$ & Dry air flow rate out of a cooling tower segment & Per segment & $\mathrm{kg} / \mathrm{s}$ \\
\hline$F_{f}$ & Mass flow rate through cooling tower fan & 650.2 & $\mathrm{~kg} / \mathrm{s}$ \\
\hline$F_{w_{i n}}$ & $\mathrm{CW}$ flow rate into a cooling tower segment & Per segment & $\mathrm{kg} / \mathrm{s}$ \\
\hline$F_{w_{o u t}}$ & CW flow rate out of a cooling tower segment & Per segment & $\mathrm{kg} / \mathrm{s}$ \\
\hline$F_{w_{e v a p}}$ & Water evaporating rate per cooling tower segment & Per segment & $\mathrm{kg} / \mathrm{s}$ \\
\hline$h_{a}$ & Cooling tower air phase heat transfer coefficient & 0.6658 & $\mathrm{~W} /\left(\mathrm{m}^{2} \cdot \mathrm{K}\right)$ \\
\hline$h_{C T B}$ & Height of Cooling Tower Basin & 13.2 & $\mathrm{~m}$ \\
\hline$h_{D}$ & Cooling tower air phase mass transfer coefficient & 0.000657 & $\mathrm{~kg} /\left(\mathrm{m}^{2} \cdot \mathrm{s}\right)$ \\
\hline$h_{w}$ & Cooling tower water phase heat transfer coefficient & 64.395 & $\mathrm{~W} /\left(\mathrm{m}^{2} \cdot \mathrm{K}\right)$ \\
\hline
\end{tabular}

Table 1: Model variables and parameters (1). 


\begin{tabular}{|c|c|c|c|}
\hline Symbol & Description & $\begin{array}{l}\text { Steady-state } \\
\text { value }\end{array}$ & Units \\
\hline$I_{M a x C T B}$ & Cooling tower basin maximum $\mathrm{CW}$ inventory & $10,058,400$ & $\mathrm{~kg}$ \\
\hline$k_{H X_{i}}$ & $\begin{array}{l}\text { Heat Exchanger hydraulic flow coeficient for stream } \\
\text { i }\end{array}$ & $\begin{array}{l}\text { Per ex- } \\
\text { changer }\end{array}$ & $\left.\mathrm{kg} / \mathrm{s} \cdot \sqrt{\frac{k g}{m^{3} P a}}\right)$ \\
\hline$k_{P 1}$ & $\begin{array}{l}\text { Rotating equipment power transient response state } \\
\text { space coefficient } 1\end{array}$ & 1.48 & dimensionless \\
\hline$k_{P 2}$ & $\begin{array}{l}\text { Rotating equipment power transient response state } \\
\text { space coefficient } 2\end{array}$ & 0.52 & dimensionless \\
\hline$k_{P 3}$ & $\begin{array}{l}\text { Rotating equipment power transient response state } \\
\text { space coefficient } 3\end{array}$ & 1.48 & dimensionless \\
\hline$n$ & Fan rotational speed & 2.0 & $\begin{array}{l}\text { Revolutions } \\
\text { per second }\end{array}$ \\
\hline$p_{a_{\text {out }}}$ & Pressure of moist air leaving the cooling tower & 100212 & $\mathrm{~Pa}$ \\
\hline$p_{d a}$ & Pressure of dry air coming into cooling tower & 100,000 & $\mathrm{~Pa}$ \\
\hline$p_{f}$ & Pressure head generated by cooling tower fan & 211.9 & $\mathrm{~Pa}$ \\
\hline$p_{p}$ & Pump discharge differential pressure & 736,600 & $\mathrm{~Pa}$ \\
\hline$p_{s}$ & Standard atmospheric pressure & 100,000 & $\mathrm{~Pa}$ \\
\hline$p_{w_{C T i n}}$ & Pressure of CWR coming into cooling tower & 250,000 & $\mathrm{~Pa}$ \\
\hline$p_{w_{C T \text { out }}}$ & Pressure of $\mathrm{CW}$ at the bottom of the cooling tower & 100,000 & $\mathrm{~Pa}$ \\
\hline$p_{\text {wvap }}$ & Water vapour pressure at the interface & Per segment & $\mathrm{Pa}$ \\
\hline$P_{f}$ & Cooling tower fan power consumption & $137,006.8$ & $\mathrm{~W}$ \\
\hline$P_{p}$ & Pump power consumption & $932,989.9$ & $\mathrm{~W}$ \\
\hline$R_{E P}$ & $\begin{array}{l}\text { Equal Percentage control valve characteristic con- } \\
\text { stant }\end{array}$ & 40 & dimensionless \\
\hline$T_{a}$ & Cooling tower air segment temperature & Per segment & Kelvin \\
\hline$T_{a_{i n}}$ & Temperature of dry air coming into cooling tower & 298 & Kelvin \\
\hline$T_{a_{\text {out }}}$ & Temperature of moist air leaving cooling tower & 301.2 & Kelvin \\
\hline$T_{\text {int }}$ & Cooling tower interface temperature & Per segment & Kelvin \\
\hline
\end{tabular}

Table 2: Model variables and parameters (2). 


\begin{tabular}{|c|c|c|c|}
\hline Symbol & Description & $\begin{array}{l}\text { Steady-state } \\
\text { value }\end{array}$ & Units \\
\hline$T_{w}$ & Cooling tower water temperature & Per segment & Kelvin \\
\hline$U$ & Heat exchanger overall heat transfer coefficient & $\begin{array}{l}\text { Per ex- } \\
\text { changer }\end{array}$ & $\mathrm{W} /\left(\mathrm{m}^{2} \cdot \mathrm{K}\right)$ \\
\hline$V_{a_{s e g}}$ & Volume of air in one Cooling Tower segment & 147.04 & $\mathrm{~m}^{3}$ \\
\hline$V_{w_{\text {seg }}}$ & Volume of water in one Cooling Tower segment & 29.3 & $\mathrm{~m}^{3}$ \\
\hline$Y_{a}$ & Cooling tower air absolute humidity & Per segment & $\begin{array}{l}\text { kg water per } \\
\text { kg dry air }\end{array}$ \\
\hline$Y_{\text {int }}$ & Cooling tower interface absolute humidity & Per segment & $\begin{array}{l}\mathrm{kg} \text { water per } \\
\mathrm{kg} \text { dry air }\end{array}$ \\
\hline$\Delta T_{l m}$ & Logarithmic Mean Temperature Difference (LMTD) & $\begin{array}{l}\text { Per ex- } \\
\text { changer }\end{array}$ & $\mathrm{K}$ \\
\hline$\lambda$ & Latent heat of vaporisation of water & $2,257,000$ & $\mathrm{~J} / \mathrm{kg}$ \\
\hline$\xi_{a}$ & Volume fraction of air in the cooling tower & 0.50 & Fraction \\
\hline$\xi_{w}$ & Volume fraction of water in the cooling tower & 0.1 & Fraction \\
\hline$\rho_{a}$ & Density of air at $25^{\circ} \mathrm{C}$ & 1.1694 & $\mathrm{~kg} / \mathrm{m}^{3}$ \\
\hline$\rho_{w}$ & Density of water & 1000 & $\mathrm{~kg} / \mathrm{m}^{3}$ \\
\hline$\tau_{p_{C T i n}}$ & $\begin{array}{l}\text { Dynamic pressure time constant for cooling water } \\
\text { return entering the cooling tower }\end{array}$ & 60 & seconds \\
\hline$\tau_{p_{a_{o u t}}}$ & $\begin{array}{l}\text { Dynamic pressure time constant for moist air leaving } \\
\text { cooling tower }\end{array}$ & 60 & seconds \\
\hline$\tau_{\Delta p_{H X 1}}$ & $\begin{array}{l}\text { Dynamic differential pressure time constant for } \\
\text { stream } 1 \text { of heat exchanger }\end{array}$ & 60 & seconds \\
\hline$\tau_{\Delta p_{H X 2}}$ & $\begin{array}{l}\text { Dynamic differential pressure time constant for } \\
\text { stream } 2 \text { of heat exchanger }\end{array}$ & 60 & seconds \\
\hline
\end{tabular}

Table 3: Model variables and parameters (3). 


\begin{tabular}{|l|l|l|l|}
\hline Symbol & Description & $\begin{array}{l}\text { Steady-state } \\
\text { value }\end{array}$ & Units \\
\hline$\tau_{T_{H X 2}}$ & $\begin{array}{l}\text { Dynamic temperature time constant for stream 2 of } \\
\text { heat exchanger output }\end{array}$ & 360 & seconds \\
\hline$\tau_{\Delta p_{C V}}$ & $\begin{array}{l}\text { Dynamic pressure time constant for pressure drop } \\
\text { over control valve }\end{array}$ & 10 & seconds \\
\hline$\omega$ & Pump rotational speed & 12.33 & $\begin{array}{l}\text { Revolutions } \\
\text { per second }\end{array}$ \\
\hline
\end{tabular}

Table 4: Model variables and parameters (4).

performance of Cooling Towers (CTs): The Poppe, Merkel, and e-NTU methods. These methods, although helpful, do not provide dynamic models that can be used for control and optimisation. Few dynamic models that describe cooling tower unit operation are available in the literature; see for example the dynamic, first principles models built by Li, Li and Seem [8] and Löfgren [9] that are used as a basis for the work described in this paper. In both [8] and [9] the authors developed dynamic models for a cooling tower by dividing the tower into segments like the authors have done in this paper. However in $[8]$ the air side transient mass and energy transfer is neglected, whereas it is included in 9. It is also included in this paper in more detail, as the equations in [9] do not contain all the relevant detail for a numerical simulation of the cooling towers modelled in this paper.

For a number of the cooling tower models found in the literature (e.g. in McCabe et al. [10]), as well as for practical operation, the wet bulb temperature is a key variable to be calculated (Green and Perry [11]). A model for this variable is defined by Stull [12. Stull shows that the wet-bulb temperature depends on ambient temperature $\left(T_{a}\right)$ and humidity $\left(Y_{a}\right)$, and both these variables are included in the model derived in this paper.

Fisenko et al. [13] constructed a detailed steady-state model for the evaporative cooling of a cooling tower, where it is assumed that all the water flow 
that happens in the cooling tower, is in the form of droplets. Similarly, in this paper, all heat and mass transfer is modelled as occurring between droplets and the surrounding air flow. The average droplet radius is assumed to be $1 \mathrm{~mm}$, and the total volume of packing per cooling tower is assumed $1161 \mathrm{~m}^{3}$ as per the design data. Similarly to [14, the volume fraction in the cooling tower that is water, is assumed to be $10 \%$. The contact area $\left(a_{c t}\right)$ for heat and mass transfer can be calculated from these assumed values.

In 11 as well as [5], the mass balance for the cooling tower includes the makeup, evaporation, and blowdown streams in addition to the main in and outflow of cooling water into and from the tower. An assumption about the number of concentration cycles in the system is included in most models (Castro et al. [2]). In this paper, the mass balance is modelled with the streams as indicated in Figure 2 for each cooling tower. It is assumed that if the cooling tower fan ${ }_{135}$ (see section 3.2) is switched off, then the cool dry air flowing into the tower $\left(F_{a_{i n}}\right)$ is zero.

In Figure 2, the level in the basin below the cooling tower is shared between all 3 cooling towers, and is modelled as an integrator.

In [15, the cooling tower outlet temperature is modelled as a function of the flow rates and temperatures of the streams indicated in Figure 2, as well as the cooling water thermal effectiveness. In [3], an enthalpy balance is used to model the cooling tower, with the mass transfer coefficient of the packing determined experimentally due to the complex surface geometries of the cooling tower fillings. In [16], Ponce-Ortegaa et al. constructed a still more detailed enthalpy model.

Al-Nimr [17] constructed a simple dynamic model for a cooling tower where both the sensible and latent heat transfer is taken into account. In [8], the dependence of the water density on temperature in each water cell is included in a dynamic model. Ma et al. [18, built a simplified dynamic model of the cooling tower, without discussing the details of model derivation. In [19, the heat transmitted by convection to the packing in the tower was included in the dynamic model. 


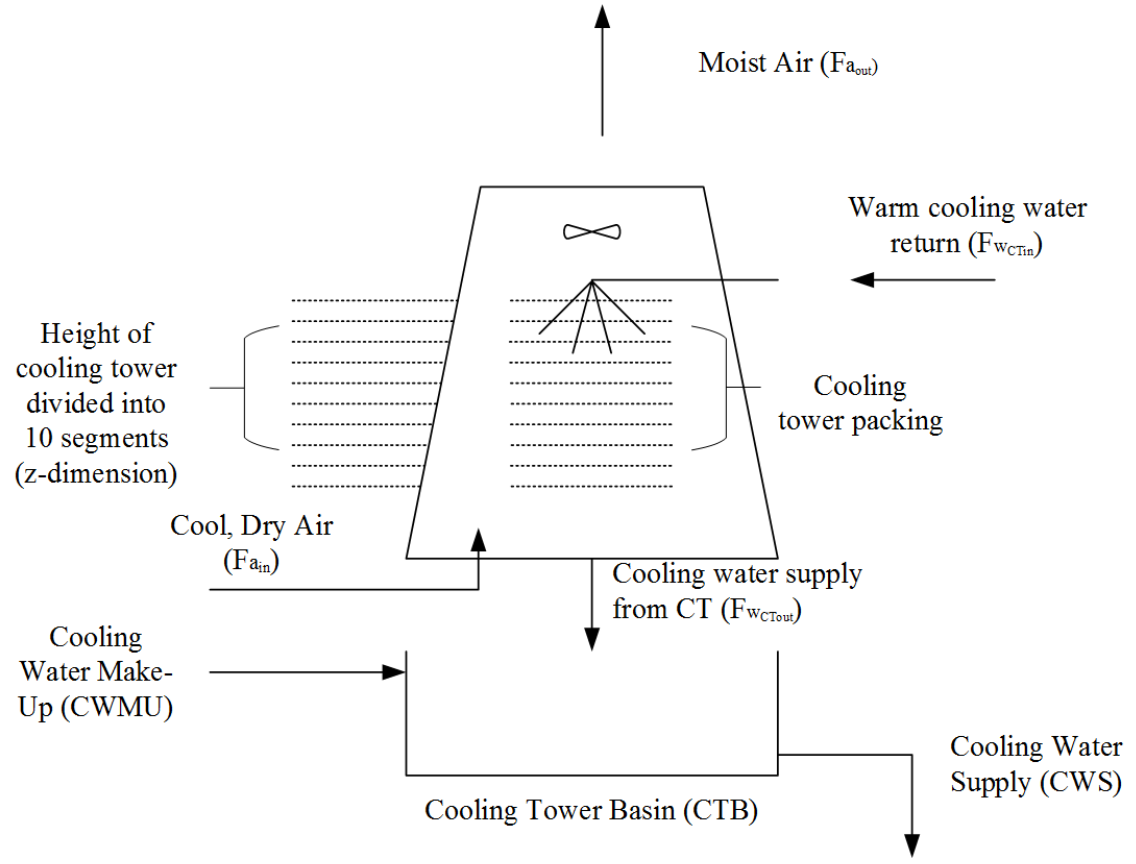

Figure 2: Main streams in and out of each cooling tower.

For this paper, the cooling tower height is divided into 10 segments of equal height and volume to be modelled (see Figure 2). The design dimensions of the tower were used to size each segment.

The interface between the water bulk and the air bulk is often assumed to be saturated, i.e. the relative humidity is $100 \%$ [20]. This is also the approach taken in this paper. Each water droplet in the cooling tower is modelled as shown in Figure 3. Drops are aggregated into the 10 different segments with key variables describing the characteristics of each segment. The interface between the water and the air phases are modelled as shown in Figure 3 .

Central to developing a dynamic model for the cooling tower is modelling the mass and heat transfers that occur in the tower. Middleman 21 uses a molar flux equation at low rates of evaporation. In this equation, the mass transfer rate of evaporated water into the air is directly proportional to the difference in the molar fraction of the water vapour at the interface, and the molar fraction 


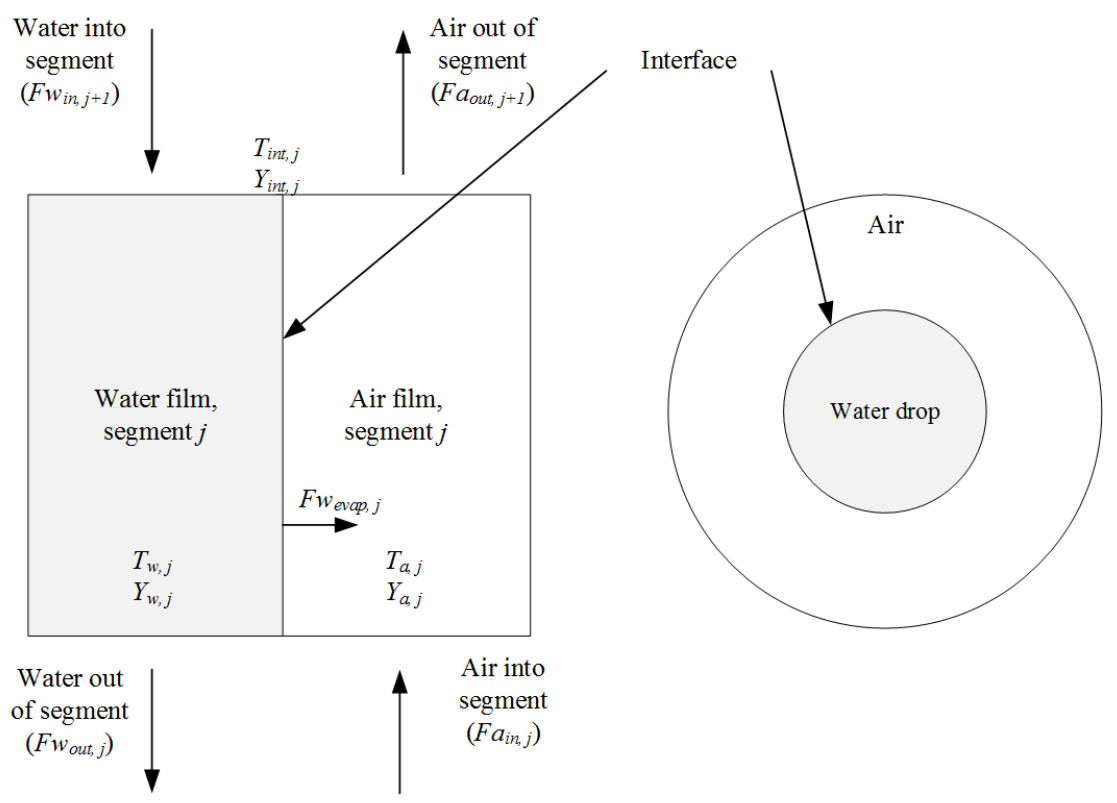

Figure 3: The main variables and interface for the $\mathrm{j}^{\text {th }}$ segment of the cooling tower.

of water of the bulk air. Since the dynamic transient of the heat transfer rate to reach steady state in the interface is assumed to be fast (Marques et al. [14]), a steady state energy balance equation can be used for the interface of the $\mathrm{j}^{\text {th }}$ segment in the tower as follows:

$$
h_{w} a_{c t}\left(T_{w, j}-T_{i n t, j}\right)=h_{a} a_{c t}\left(T_{i n t, j}-T_{a, j}\right)+h_{D} \lambda a_{c t}\left(Y_{i n t, j}-Y_{a, j}\right) .
$$

Here, $h_{D}$ is the cooling tower air phase mass transfer coefficient, $\lambda$ is the latent heat of vaporisation of water, $a_{c t}$ is the cooling tower contact area of water surface per volume unit in the tower, $Y$ is absolute humidity, $h_{a}$ is the cooling tower air phase heat transfer coefficient, $h_{w}$ is the cooling tower water phase heat transfer coefficient, and $T$ is temperature. The symbols used were chosen this way $(h)$ with subscripts indicating which specific quantity is being referred to, since the same symbols for heat and mass transfer coefficients were used in 
some of the most prominent articles on cooling tower modelling: E.g. [14, 7]

$$
F_{w_{o u t}, j}=F_{w_{i n}, j+1}-F_{w_{\text {evap }}, j} .
$$

From the energy balance for the water film in (5), the water temperature in the $\mathrm{j}^{\text {th }}$ segment, $T_{w, j}$, can be calculated [14] as

$$
\xi_{w} \rho_{w} c_{w} \frac{\partial T_{w, j}}{\partial t}=\frac{F_{w, j}}{a_{h}} c_{w} \frac{\partial T_{w, j}}{\partial z}-h_{w} a_{c t}\left(T_{w, j}-T_{i n t, j}\right),
$$


where $\xi_{w}$ is the volume fraction of water in the $\mathrm{j}^{\text {th }}$ cooling tower segment, $\rho_{w}$ is the density of water, $c_{w}$ is the heat capacity of water, $z$ is the vertical dimension in the tower, and $a_{h}$ is the horizontal cross-sectional area of the $\mathrm{j}^{\text {th }}$ cooling tower segment. Similarly from the energy balance for the air film in (6), the air temperature in the $\mathrm{j}^{\text {th }}$ segment, $T_{a, j}$, can be calculated [14] as

$$
\xi_{a} \rho_{a} c_{a} \frac{\partial T_{a, j}}{\partial t}=-\frac{F_{a, j}}{a_{h}} c_{a} \frac{\partial T_{a, j}}{\partial z}-h_{a} a_{c t}\left(T_{a, j}-T_{i n t, j}\right),
$$

where $\xi_{a}$ is the volume fraction of air in the cooling tower, $\rho_{a}$ is the density of air and $c_{a}$ is the heat capacity of air. The default ambient air temperature $\left(T_{a_{i n}}\right)$ is $25^{\circ} \mathrm{C}$, but it is changed as part of the model fit and step testing that was done. The ambient cooling tower inlet air density and heat capacity is adjusted using the Peng Robinson equations of state. From the mass balance in (7), the air humidity for segment $\mathrm{j}, Y_{a, j}$, can be written as follows:

$$
\xi_{a} \rho_{a} \frac{\partial Y_{a, j}}{\partial t}=-\frac{F_{a, j}}{a_{h}} \frac{\partial Y_{a, j}}{\partial z}+h_{D} a_{c t}\left(Y_{i n t, j}-Y_{a, j}\right)
$$

In [13, Fisenko et al. used relations to calculate the temperature dependence of mass and heat transfer coefficients as a function of temperature. The re215 lationship between the air mass transfer coefficient, and the air heat transfer coefficient, has been modelled in [24] and [22]. According to [10], the following relation can be used for air-water cooling tower systems:

$$
\frac{h_{a}}{h_{D}}=c_{a}
$$

The pressure drop over the cooling tower is focused on the water spray nozzle at the top of the tower. The nozzle is modelled with an orifice equation (9) 
relating pressure drop (observed at 2.5 barg in the real plant process data) and flow $\left(F_{w_{\text {CT Tin }}}\right)$ through the nozzle as

$$
\frac{F_{w_{C T \text { in }}}}{\rho_{w}}=C_{v C T} \cdot \sqrt{\frac{p_{w_{C T \text { in }}}-p_{w_{C T \text { out }}}}{\rho_{w}}},
$$

where $C_{v C T}$ is the $\mathrm{C}_{\mathrm{v}}$ of the valve, and $\rho_{w}$ is the density of the cooling water. A first-order transfer function is used to model the dynamic change of water pressure drop over the tower in response to a change in water mass flow rate (time constant $\tau_{p_{C T \text { Tin }}}$ ).

\subsection{Fan modelling}

Mechanical power, generated by the electric motor of each fan is partly converted to hydraulic work by the cooling tower fan, based on the hydraulic efficiency [25]. In [8], the first two fan affinity laws are shown that relates flow through the fan $\left(F_{f}\right)$, pressure head created $\left(p_{f}\right)$, and power $\left(P_{f}\right)$ to fan speed $(n)$, from one steady-state operating point (point 0 ) to another one (point 1) as follows:

$$
\begin{aligned}
& F_{f 1}=F_{f 0}\left(\frac{n_{1}}{n_{0}}\right) \\
& p_{f 1}=p_{f 0}\left(\frac{n_{1}}{n_{0}}\right)^{2} \\
& P_{f 1}=P_{f 0}\left(\frac{n_{1}}{n_{0}}\right)^{3}
\end{aligned}
$$

The dynamic transient of the pressure head (11) created by the fan as a function of fanspeed is modelled with a first-oder response with time constant of $\tau_{p_{a_{\text {out }}}}$.

In [26] and 27] the power benefits are shown that can be obtained by using Variable Speed Drives (VSDs), especially for fans given the highly non-linear relationship between fan speed and power consumption. 
In 28, Sen points out that the starting current of induction motors can exceed steady-state current by $500 \%$ to $800 \%$. This translates into very high power consumption during start-up which is a concern as most fans and pumps in industrial plants are driven by induction motors, including the fans and pumps studied in this paper.

In [29, Szymczyk and Karaskiewicz modelled and simulated the initial transients of $11,500 \mathrm{~m}^{3} / \mathrm{h}$ centrifugal induction water pumps after start-up of the pump. The pumps exhibited an underdamped dynamic response for the power consumption. The overshoot was around $120 \%$, and the pumps reached steadystate in fewer than 30 seconds. For this paper, the cooling tower fan power and pump power were modelled with a similar dynamic power transient. The power overshoot is important for optimisation and control from a hybrid system perspective, as it will deter fans or pumps from being switched on unnecessarily if power minimisation forms part of the control objectives.

Based on the above, the fan power is modelled as an underdamped second order system with two state variables, $X_{1_{P f}}$ and $X_{2_{P f}}$, where $k_{P 1}, k_{P 2}$ and $k_{P 3}$ are constant coefficients, and $P_{f_{s s}}$ is the steady-state fan power consumption. The static and dynamic models are thus combined similar to a Hammerstein model consisting of a static valued non-linear element combined with a following linear dynamic element (a similar approach was also used for other variables in 255 the plant as per the below sections).

$$
\begin{aligned}
X_{1_{P f}} & =P_{f} \\
\frac{d X_{1_{P f}}}{d t} & =X_{2_{P f}} \\
\frac{d X_{2_{P f}}}{d t} & =-k_{P 1} X_{1_{P f}}-k_{P 2} X_{2_{P f}}+k_{P 3} P_{f_{s s}}
\end{aligned}
$$

$P_{f}$ is then updated by integrating $\frac{d X_{1_{P f}}}{d t}$. 


\subsection{Cooling tower basin modelling}

The mass inventory in the cooling tower basin is modelled through the following mass balance:

$$
\frac{d I_{C T B}}{d t}=\sum_{i=1}^{3} F_{w_{C T o u t}, i}+F_{C W M U}-F_{C W S}
$$

260

where $I_{C T B}$ is the basin mass inventory of water, $F_{w_{C T \text { out }}, i}$ is the mass flow rate of water out of the $\mathrm{i}^{\text {th }}$ cooling tower, $F_{C W M U}$ is the mass flow rate of water make-up, and $F_{C W S}$ is the mass flow rate of water from the basin as Cooling Water Supply.

265 Assuming perfect mixing of the water in the basin [14, the energy balance of the basin is given by

$c_{w} I_{C T B} \frac{d T_{C T B}}{d t}=\sum_{i=1}^{3} c_{w} F_{w_{C T o u t}, i} T_{w_{C T o u t}, i}+c_{w} F_{C W M U} T_{C W M U}-c_{w} F_{C W S} T_{C T B}$,

where the temperatures of the various streams are multiplied by their flow rates and summed. $F_{C W S}$ is determined by the unit operation down stream of the basin (pumps), which in turn depends on the pressure at the bottom of the basin. This pressure, $p_{C T B}$, is given by

$$
p_{C T B}=\rho_{w} g h_{C T B} \frac{I_{C T B}}{I_{M a x C T B}}+p_{s}
$$

where $\rho_{w}$ is the density of water, $g$ is the gravitational constant, $h_{C T B}$ is the design height of the cooling tower basin, and $I_{M a x C T B}$ is the maximum mass inventory of the basin. 


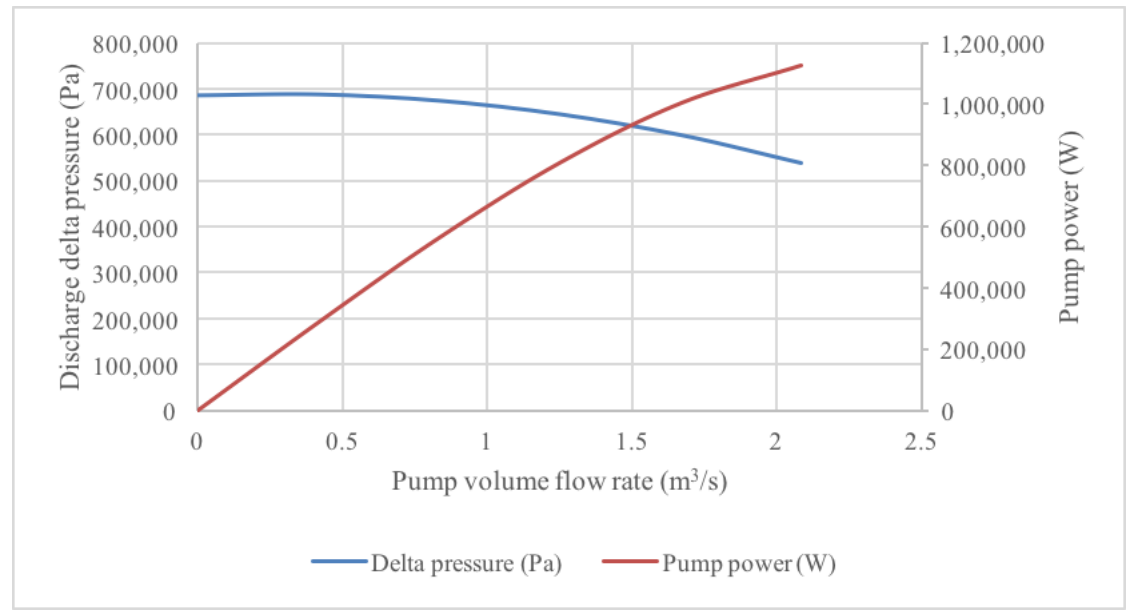

Figure 4: Pump curves for the pumps - $\Delta p_{p}$ vs. $F$ and $P_{p_{s s}}$ vs. $F$.

\subsection{Pump modelling}

In [3] and [15 it is recommend to use a second degree polynomial to represent a pump curve. In [30, Wang and Chen use a second degree polynomial to also model pump output differential pressure $\left(\Delta p_{p}\right)$ as a function of rotational speed $(\omega)$ and mass flow rate $(F)$ :

$$
\Delta p_{p}=a_{p_{0}} \omega^{2}+a_{p_{1}} \omega \frac{F}{\rho_{w}}+a_{p_{2}} \frac{F^{2}}{\rho_{w}^{2}}
$$

The steady-state power consumption of the pump $\left(P_{p_{s s}}\right)$ can be calculated as per (18) if mechanical losses are assumed to be negligible [30]:

$$
P_{p_{s s}}=F \frac{\Delta p_{p}}{\rho_{w}}
$$

For the pumps modelled in this paper, 17 and 18 yield the pump curves as displayed in Figure 4 


\subsection{Hydraulic network modelling}

The temperature of the resultant stream flowing from a mixer (assuming no phase changes are occuring in the mixer), is modelled as the sum of the temperatures of the input streams weighted by the mass flow rate per input stream [3, 5].

The pressure drop over a segment of pipe is calculated in [15] which uses the fact that parallel branches of flow must have equal pressure drop as part of the over-all hydraulic solution of the network (see also 31]). Parallel branches in a heat exchanger, valve and pipe network can then be solved as a linear system as per 15 .

For this paper an algorithm was developed to model the distribution of mass flow of cooling water through the parallel network of heat exchangers. The pressure drop $\left(\Delta p_{e_{i}}\right)$ and mass flow rate $\left(F_{e_{i}}\right)$ through each valve or exchanger 300 ( $\mathrm{i}^{\text {th }}$ element in branch) in each branch of the network, will follow the rule in (19).

$$
\Delta p_{e_{i}}=k_{i} F_{e_{i}}^{2}
$$

Using 19, the pressure drop over the entire applicable branch $\Delta p_{j}\left(\mathrm{j}^{\text {th }}\right.$ branch) is given by (20) where there are $n$ valves or exchangers in the branch.

$$
\begin{aligned}
& \Delta p_{j}=\sum_{i=1}^{n} k_{i} F_{e_{i}}^{2} \\
& \Delta p_{j}=F_{j}^{2} \sum_{i=1}^{n} k_{i} \\
& K_{j}=\sqrt{\sum_{i=1}^{n} k_{i}} \\
& \sqrt{\Delta p_{j}}=F_{j} K_{j}
\end{aligned}
$$


In (20), the mass flow is common to all terms and can be removed from the

305 taken the square root of to become $K_{j}$ for the $\mathrm{j}^{\text {th }}$ branch in the network, out of a total of $m$ branches as per 22 . $K_{j}$ can be calculated at each iteration of the simulation by using the square root of the pressure drop, and the mass flow as per 23).

310 at all times, and the sum of the flows $F_{j}$ through the network will be equal to the known total inflow to the network $\left(F_{\text {total }}\right)$. With these constraints, a system of linear equations with $m$ unknowns and $m$ equations can be constructed and solved for the different flows through the network (24). Once the flows are the network.

$$
\left[\begin{array}{cccccc}
K_{1} & -K_{2} & 0 & \cdots & 0 & 0 \\
0 & K_{2} & -K_{3} & \cdots & 0 & 0 \\
\vdots & \vdots & \ddots & \ddots & \vdots & \vdots \\
0 & 0 & 0 & \ddots & -K_{m-1} & 0 \\
0 & 0 & 0 & \ddots & K_{m-1} & -K_{m} \\
1 & 1 & 1 & \cdots & 1 & 1
\end{array}\right]\left[\begin{array}{c}
F_{1} \\
F_{2} \\
F_{3} \\
\vdots \\
F_{m-1} \\
F_{m}
\end{array}\right]=\left[\begin{array}{c}
0 \\
0 \\
0 \\
\vdots \\
0 \\
F_{\text {total }}
\end{array}\right]
$$

\subsection{Control valve modelling}

Most authors use a quadratic relationship scaled by valve opening (depending on the valve characteristic), between valve pressure drop and mass flow, where the pressure drop is scaled by the density (e.g. [1]).

The valves are modelled as per 25] in this paper [32]. The actual volume flow $\left(F / \rho_{w}\right)$ is proportional through the valve coefficient $C_{v C V}$ to the product of the valve characteristic $f($.$) , given the valve opening \left(V_{O P}\right)$, and the square root of the pressure drop over the valve $\left(\Delta p_{\text {valve }}\right)$ divided by the specific gravity 


$$
\frac{F}{\rho_{w}}=C_{v C V} \cdot f\left(V_{O P}\right) \cdot \sqrt{\frac{\Delta p_{\text {valve }}}{g_{s}}}
$$

In this paper, equal percentage flow characteristics are used for the control valves since $\Delta p_{\text {valve }}$ over the valves change depending on the operating point of

330 the cooling water circuit. Therefore, a more linear installed flow characteristic can be obtained through using the non-linear equal percentage valve characteristic 32 ]

$$
f\left(V_{O P}\right)=\left(R_{E P}\right)^{V_{O P}-1},
$$

where $R_{E P}$ is a valve design parameter.

The pressure drop over the valve is modelled to follow a first-order dynamic transient response with a time constant of $\tau_{\Delta p_{C V}}$.

\subsection{Heat exchanger modelling}

In order to calculate initial heat capacity values for the process hydrocarbon streams, as well as CW and input air streams, the Peng Robinson thermodynamic equations of state were used [33].

Various detailed heat exchanger dynamic models have been published in the literature. In [34, a cross flow heat exchanger was modelled dynamically. In [35], a dynamic model of 3 heat exchangers was built.

Thermodynamic modelling of the heat exchangers is assisted by using the concept of Logarithmic Mean Temperature Difference (LMTD) in [1] as well as in 31. The LMTD is also defined in 11] for different kinds of heat exchangers such as co-current flow and counter-current flow. It is defined in 27 with reference 


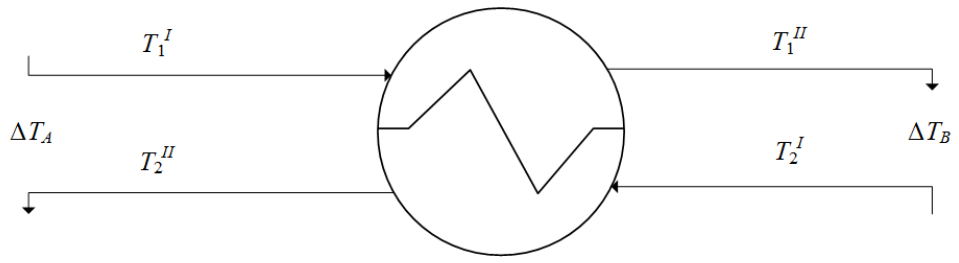

Figure 5: Generic cross-flow heat exchanger for heat exchange modelling.

to the temperatures and differential temperatures as portrayed in Figure 5

$$
\Delta T_{l m}=\frac{\Delta T_{A}-\Delta T_{B}}{\ln \frac{\Delta T_{A}}{\Delta T_{B}}}
$$

The differential temperatures are defined as follows:

$$
\begin{aligned}
& \Delta T_{A}=T_{1}^{I}-T_{2}^{I I} \\
& \Delta T_{B}=T_{1}^{I I}-T_{2}^{I}
\end{aligned}
$$

The heat energy flow in the exchanger is the product of the heat exchanger 350 $U$ factor, the heat exchange area $(A)$, and the LMTD [1, 15].

For each exchanger, 29. will apply, with $Q$ the heat duty of the exchanger, $U$ the heat transfer rate coefficient, and $A$ the total heat exchange area for the exchanger.

$$
Q=U \cdot A \cdot \Delta T_{l m}
$$

355 For each exchanger, assuming no phase changes occur over the exchanger, 30 will apply per fluid that is passing through the exchanger. Here $F$ is the mass flow rate of the fluid (stream 1 or 2 as per Figure 5), $c$ is the heat capacity of the fluid and $\Delta T$ is the temperature difference between the inlet to the exchanger and the outlet for the particular stream. The heat capacity is assumed constant 
per stream over time since the changes in temperature are relatively small.

$$
Q=F \cdot c \cdot \Delta T
$$

By solving (27) to (30) simultaneously, closed form expressions for $T_{1}^{I}, T_{1}^{I I}, T_{2}^{I}$ and $T_{2}^{I I}$ can be obtained. These temperature steady-state equations are given dynamic transients by adding a first-order time constant per exchanger $\left(\tau_{T_{H X 1}}\right.$ and $\left.\tau_{T_{H X 2}}\right)$, and turning the equations into ordinary differential equations.

Pressure losses over the exchanger are divided between bundle losses and nozzle losses according to [15], and can be approximated as a quadratic relationship between flow and pressure drop scaled by a hydraulic coefficient for stream 1 and 2 of the exchanger $\left(k_{H X_{i}}\right)$. Each exchanger's hydraulics are modelled assuming the mass flow rate is proportional to the square root of the pressure drop over the particular fluid path of the exchanger divided by the stream density, as per (31).

$$
F_{i}=k_{H X_{i}} \sqrt{\frac{\Delta p_{i}}{\rho_{i}}}
$$

The dynamic transients of the pressure drops of the two streams over the heat exchanger, are modelled with first order time constants $\tau_{\Delta p_{H X 1}}$ and $\tau_{\Delta p_{H X 2}}$.

\section{Total system model}

Pressure drops over the heat exchangers and the cooling towers will result in a particular system resistance curve as experienced by the pumps. The pump flow produced will then be at the intersection of the pump, and the network system curve. The system of equations, as developed for the total plant, will find this intersection through iteration and convergence.

The blowdown flow sent away from the cooling water circuit is on average $0.7 \%$ of the total flow in circulation, and is made-up with the make-up flow into 
the cooling tower basin. For the purposes of this paper, the blow down rate is assumed to be zero, resulting in the make-up flow in the model focusing on replacing evaporative losses, and not blow down as well. The make-up flow rate is used in a Proportional-Integral-Derivative (PID) control loop that controls the level in the cooling tower basin.

In [19, an explicit finite difference method was used to solve the system of developed dynamic Partial Differential Equations (PDEs). In this paper, numeric integration of the continuous equations are used. The system of differential and algebraic equations developed are of a stiff nature [36] for the cooling tower, but not for the rest of the plant. The Runge-Kutta $4^{\text {th }}$ order method with fixed step size (200 ms) was used to numerically solve the stiff differential equations [37, and the Euler method was used for the rest of the plant. Runge-Kutta methods are robust and accurate [37, but need small step sizes compared to system dynamics for stiff systems [36]. Fixed step size methods are preferred since all the unit operations of the cooling water circuit will be solved at the same time step as the numerical integration is performed over the simulation horizon, which is simpler with a fixed step size. The chosen step size is shown through empirical simulation to converge for all experimental simulations performed.

The complete model equations are given below, for the model as derived in Section 3 Differential state-space equations, and algebraic equations are grouped per section of the plant.

\subsection{Cooling tower model}

In the below equations the subscript $j$ refers to the $j^{\text {th }}$ section of the $\mathrm{i}^{\text {th }}$ cooling tower model. Steady-state values have $s s$ as a subscript.

\subsubsection{State space model}

$$
\frac{d p_{C T i n}}{d t}=\frac{-1}{\tau_{p_{C T \text { Tin }}}} p_{C T i n}+\frac{1}{\tau_{p_{C T \text { Tin }}}} p_{C T \text { Tinss }}
$$


For each segment $j$ :

$$
\begin{aligned}
& \frac{d T_{w, j}}{d t}=\frac{F_{w, j+1} T_{w, j+1}-F_{w, j} T_{w, j}}{\rho_{w} V_{w_{s e g}}}-\frac{h_{w} a_{s e g}\left(T_{w, j}-T_{i n t, j}\right)}{c_{w} \rho_{w} V_{w_{s e g}}} \\
& \frac{d T_{a, j}}{d t}=\frac{F_{a, j-1} T_{a, j-1}-F_{a, j} T_{a, j}}{\rho_{a} V_{a_{s e g}}}-\frac{h_{a} a_{s e g}\left(T_{a, j}-T_{i n t, j}\right)}{c_{a} \rho_{a} V_{a_{\text {seg }}}} \\
& \frac{d Y_{a, j}}{d t}=\frac{F_{a, j-1} Y_{a, j-1}+F_{w_{\text {evap }}}-F_{a, j} Y_{a, j}}{\rho_{a} V_{a_{\text {seg }}}}
\end{aligned}
$$

\subsubsection{Algebraic equations}

$$
\begin{aligned}
& h_{a}=c_{a} h_{D} \\
& p_{w_{C T \text { Tin }}}=p_{w_{C T \text { out }}}+\rho_{w}\left(\frac{F_{w_{C T \text { in }}}}{\rho_{w} C_{v C V}}\right)^{2} \\
& p_{m a_{\text {out }}}=p_{m a_{\text {in }}}+p_{f 1}
\end{aligned}
$$

For each segment $j$ :

$$
\begin{aligned}
& T_{i n t, j}=\frac{-\left(h_{D} \lambda a_{c t}\left(Y_{i n t, j}-Y_{a, j}\right)-h_{a} a_{c t} T_{a, j}-h_{w} a_{c t} T_{w, j}\right)}{h_{a} a_{c t}+h_{w} a_{c t}} \\
& Y_{\text {int }, j}=0.622 \frac{P_{w v a p, j}}{P_{s}-P_{w v a p, j}} \\
& F_{w_{\text {evap }}, j}=h_{D} a_{\text {segment }}\left(Y_{\text {int }, j}-Y_{a, j}\right) \\
& F_{w_{\text {out }}, j}=F_{w_{\text {in }}, j+1}-F_{w_{\text {evap }}, j}
\end{aligned}
$$




\subsection{Fan model}

4.2.1. State space model

$$
\begin{aligned}
& \frac{d p_{a_{\text {out }}}}{d t}=\frac{-1}{\tau_{p_{a_{\text {out }}}}} p_{a_{\text {out }}}+\frac{1}{\tau_{p_{a_{\text {out }}}}} p_{a_{\text {out }}} \\
& \frac{d X_{1_{P f}}}{d t}=X_{2_{P f}} \\
& \frac{d X_{2_{P f}}}{d t}=-k_{P 1} X_{1_{P f}}-k_{P 2} X_{2_{P f}}+k_{P 3} P_{f_{s s}}
\end{aligned}
$$

4.2.2. Algebraic equations

$$
\begin{aligned}
& F_{f 1}=F_{f 0}\left(\frac{n_{1}}{n_{0}}\right) \\
& p_{f 1}=p_{f 0}\left(\frac{n_{1}}{n_{0}}\right)^{2} \\
& P_{f 1}=P_{f 0}\left(\frac{n_{1}}{n_{0}}\right)^{3} \\
& P_{f a n}=P_{f x 1}
\end{aligned}
$$

415

.3. Cooling tower basin model

4.3.1. State space model

$$
\begin{aligned}
\frac{d I_{C T B}}{d t} & =\sum_{i=1}^{3} F_{w_{C T \text { out }}, i}+F_{C W M U}-F_{C W S} \\
\frac{d T_{C T B}}{d t} & =\frac{\sum_{i=1}^{3} F_{w_{C T o u t}, i} T_{w_{C T o u t}, i}+F_{C W M U} T_{C W M U}-F_{C W S} T_{C T B}}{I_{C T B}}
\end{aligned}
$$




\subsubsection{Algebraic equations}

$$
p_{C T B}=p_{C W S}=\rho_{w} g h_{C T B} \frac{I_{C T B}}{I_{M a x C T B}}+p_{s}
$$

\subsection{Splitter and mixer around pumps model}

${ }_{420}$ The flow through each pump is determined by the pressure increase over the pump, which is defined by (53).

\subsection{Pump model}

\subsubsection{State space model}

For each pump:

$$
\begin{aligned}
& \frac{d P_{p x 1}}{d t}=P_{p x 2} \\
& \frac{d P_{p x 2}}{d t}=-k_{P 1} P_{p x 1}-k_{P 2} P_{p x 2}+k_{P 3} P_{p_{s s}}
\end{aligned}
$$

${ }_{425} P_{p x 1}$ is the current pump power, and is solved by integrating $\frac{d P_{p x 1}}{d t}$.

\subsubsection{Algebraic equations}

For each pump:

$$
\begin{aligned}
& \Delta p_{p}=p_{E C W S}-p_{C W S} \\
& F_{p}=\rho_{w} \frac{-a_{p_{1}} \omega+\sqrt{\left(a_{p_{1}} \omega\right)^{2}-4 a_{p_{2}}\left(a_{p_{0}} \omega^{2}-\Delta p_{p}\right)}}{2 a_{p_{2}}} \\
& P_{p_{s s}}=F \frac{\Delta p_{p}}{\rho_{w}}
\end{aligned}
$$


4.6. Heat exchanger network splitter and mixer model

${ }_{430}$ The flow through each branch in the heat exchanger network, as well as the pressure upstream of the network, are modelled by the algorithm given in Section 3.5 , and 23 and 24 .

4.7. Control valve model

4.7.1. State space model

$$
\frac{d \Delta p_{C V}}{d t}=\frac{-1}{\tau_{\Delta p_{C V}}} \Delta p_{C V}+\frac{1}{\tau_{\Delta p_{C V}}} \Delta p_{C V_{s s}}
$$

435

4.7.2. Algebraic equations

$$
\begin{aligned}
& f\left(V_{O P}\right)=\left(R_{E P}\right)^{V_{O P}-1} \\
& \Delta p_{C T_{s s}}=g_{s}\left(\frac{F}{\rho_{w} C_{v C V} \cdot f\left(V_{O P}\right)}\right)^{2}
\end{aligned}
$$

\subsection{Heat exchanger model}

For each heat exchanger ( $i$ refers to either stream 1 or stream 2 of the heat exchanger):

440 4.8.1. State space model

$$
\begin{aligned}
& \frac{d \Delta p_{H X i}}{d t}=\frac{-1}{\tau_{\Delta p_{H X i}}} \Delta p_{H X i}+\frac{1}{\tau_{\Delta p_{H X i}}} \Delta p_{H X i s s} \\
& \frac{d T_{H X i}}{d t}=\frac{-1}{\tau_{T_{H X i}}} T_{H X i}+\frac{1}{\tau_{T_{H X i}}} T_{H X i s s}
\end{aligned}
$$




\subsubsection{Algebraic equations}

$$
\begin{aligned}
& \Delta p_{i}=\rho_{i}\left(\frac{F_{i}}{k_{H X_{i}}}\right)^{2} \\
& K_{H X}=U A\left(\frac{1}{F_{1} c_{1}}-\frac{1}{F_{2} c_{2}}\right) \\
& T_{H X 1_{\text {outss }}}=\frac{F_{2} c_{2}\left(T_{1_{\text {in }}}+e^{K_{H X}} T_{2_{\text {in }}}-T_{2_{\text {in }}}\right)-F_{1} c_{1} T_{1_{\text {in }}}}{F_{2} c_{2} e^{K_{H X}}-F_{1} c_{1}} \\
& T_{H X 2_{\text {outss }}}=\frac{F_{1} c_{1}\left(T_{1_{\text {in }}}-T_{1_{\text {outss }}}\right)+F_{2} c_{2} T_{2_{\text {in }}}}{F_{2} c_{2}}
\end{aligned}
$$

\section{Parameter estimation}

For this paper, a data driven approach to fitting each parameter of the model as derived in the previous sections, is applied.

Least squares parameter estimation is a common technique used to fit dynamic non-linear process models 38 . However, traditional gradient decent techniques are not well suited to systems with local minima and maxima (i.e. nonconvex problems), as well as exhibiting a hybrid nature. For future research the authors recommend investigating gradient descent techniques as well for the parameter fitting task.

In [1, a genetic algorithm was chosen for the optimisation of the fitting task due to the ability of this algorithm to handle non-linear, discontinuous, multiparameter problems and its likelihood of finding a global optimum. In [39, a novel technique based on the biological DNA mechanism for utilising genetic algorithms to estimate parameters of dynamic systems in the process industries, was developed.

In [40, Kennedy and Eberhart outlines the concept of using Particle Swarm Optimisation (PSO) for the optimisation of non-linear continuous functions. 
The PSO algorithm is relatively simple, but very powerful for non-linear optimisation, including for hybrid systems [41]. PSO is an optimisation method that is built on swarm intelligence as found in nature (bee swarms, bird swarms, etc.). It is a collective, iterative method, with an emphasis on cooperation 42 . There is a large number of examples of the usage of PSO for parameter estimation in the literature. One example of PSO's application to process modelling ${ }_{465}$ is given in [43. The plant model developed in this paper has multiple local minima and maxima, therefore the PSO algorithm, being a global optimiser, is effective at finding a global optimum for the problem of fitting the parameters in the model to the plant data.

In this paper, a population of 30 particles was used. Each particle stores the 470 speed and position of all the model parameters that are to be optimised. The $\mathrm{i}^{\text {th }}$ particle in the population's $\mathrm{j}^{\text {th }}$ parameter's speed $\left(v_{j}\right)$ is updated in each optimisation iteration for each parameter:

$$
v_{j}=v_{j}+2 \theta\left(p_{j}-x_{j}\right)+2 \gamma\left(g_{j}-x_{j}\right)
$$

where $\theta$ and $\gamma$ are random real numbers between 0 and 1 evaluated for each 475 optimisation iteration, $p_{j}$ is the value of the $\mathrm{j}^{\text {th }}$ optimisation parameter for the $\mathrm{i}^{\text {th }}$ particle that has had the best performance in the latest solution space, $g_{j}$ is the position of the $\mathrm{j}^{\text {th }}$ parameter for the particle in the entire population that has had the best performance in the latest solution space, $x_{j}$ is the value of the $\mathrm{j}^{\text {th }}$ parameter of the $\mathrm{i}^{\text {th }}$ particle at the time of the iteration.

The position of the $\mathrm{j}^{\text {th }}$ parameter for the $\mathrm{i}^{\text {th }}$ particle is subsequently updated with the newly calculated speed in each iteration:

$$
x_{j_{k+1}}=x_{j_{k}}+v_{j}
$$

The performance of each particle is evaluated at each iteration, by evaluating 
the objective function of the optimiser with predictive horizon $N$. In this paper,

predictive horizon spans the entire dataset that is being fitted against for each parameter. The objective function sums the square of the error between the variable being fitted, and the real plant data for the variable, over the length of the prediction horizon.

In [14, Marques et al. also fitted their model utilising inlet and outlet temperatures and flow rate. The approach of [14] was used in this paper in order to make use of the available data, as well as the model with parameters as developed. The cooling tower hydraulic flow coefficient is estimated from the measured cooling tower inlet pressure data.

In order to increase the accuracy of the individual equipment models, the preferred approach taken was to fit each piece of equipment separately to plant data where possible, and then combine all the fitted equipment into the total model. The remaining parameters were then estimated. Initial values for all parameters were obtained from design data and equipment data sheets. The parameters to be fitted were then identified as the ones that are either not available in the data sheets to begin with, or that are most likely to be different in the actual plant from the datasheet values.

For the cooling towers, the parameters to be fitted are the mass transfer coefficient of air $\left(h_{D}\right)$, the heat transfer coefficient of the water $\left(h_{w}\right)$, and the heat transfer coefficient of the air $\left(h_{a}\right)$. These parameters were fitted for the cooling tower, using cooling tower design sheet data, and then adjusted by fitting them to the actual data. The fitted parameters are shown in Table 5.

The cooling tower model was fitted by comparing the simulated Cooling Water Supply temperature to actual plant data for two periods, as can be seen in Figure 6 and 7. The first period is from $12 \mathrm{am}$ at midnight to $12 \mathrm{pm}$ noon. For the second period the simulation was run over a 6-hour period from 9:40 $\mathrm{pm}$. The CWS temperature is the best available variable to validate the model with as it affects the plant the most, and is the only important output variable that is measured. The model responds as expected to ambient temperature, humidity, as well as Cooling Water Return temperature changes. The variation 
Table 5: Cooling tower coefficients fitted to plant data.

\begin{tabular}{|l|l|l|l|}
\hline Parameter & Description & $\begin{array}{l}\text { Fitted to } \\
\text { plant data }\end{array}$ & Units \\
\hline$h_{D}$ & $\begin{array}{l}\text { Cooling Tower mass trans- } \\
\text { fer coefficient }\end{array}$ & 0.000657 & $\mathrm{~kg} /\left(\mathrm{m}^{2} \cdot \mathrm{s}\right)$ \\
\hline$h_{w}$ & $\begin{array}{l}\text { Water heat transfer coeffi- } \\
\text { cient in cooling tower }\end{array}$ & 64.395 & $\mathrm{~W} /\left(\mathrm{m}^{2} \cdot \mathrm{K}\right)$ \\
\hline$h_{a}$ & $\begin{array}{l}\text { Air heat transfer coeffi- } \\
\text { cient in cooling tower }\end{array}$ & 0.6658 & $\mathrm{~W} /\left(\mathrm{m}^{2} \cdot \mathrm{K}\right)$ \\
\hline
\end{tabular}

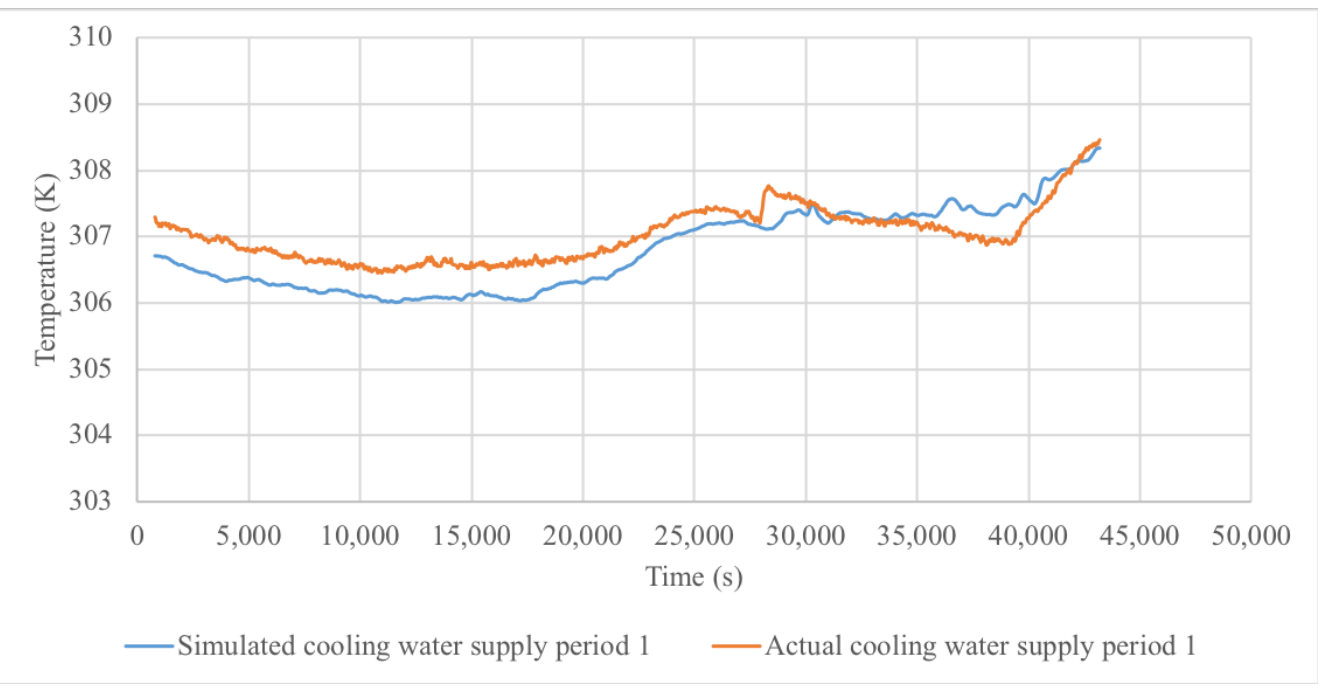

Figure 6: Cooling water supply temperature $\left(T_{C W S}\right)$ simulation vs. actual for period 1.

515 relative humidity change, and the Cooling Water Return temperature varied 5 Kelvin over the testing period. The $\mathrm{R}^{2}$ coefficient of determination for the cooling tower fit is 0.76 .

Since more instruments providing plant data is available for the 10 bigger 


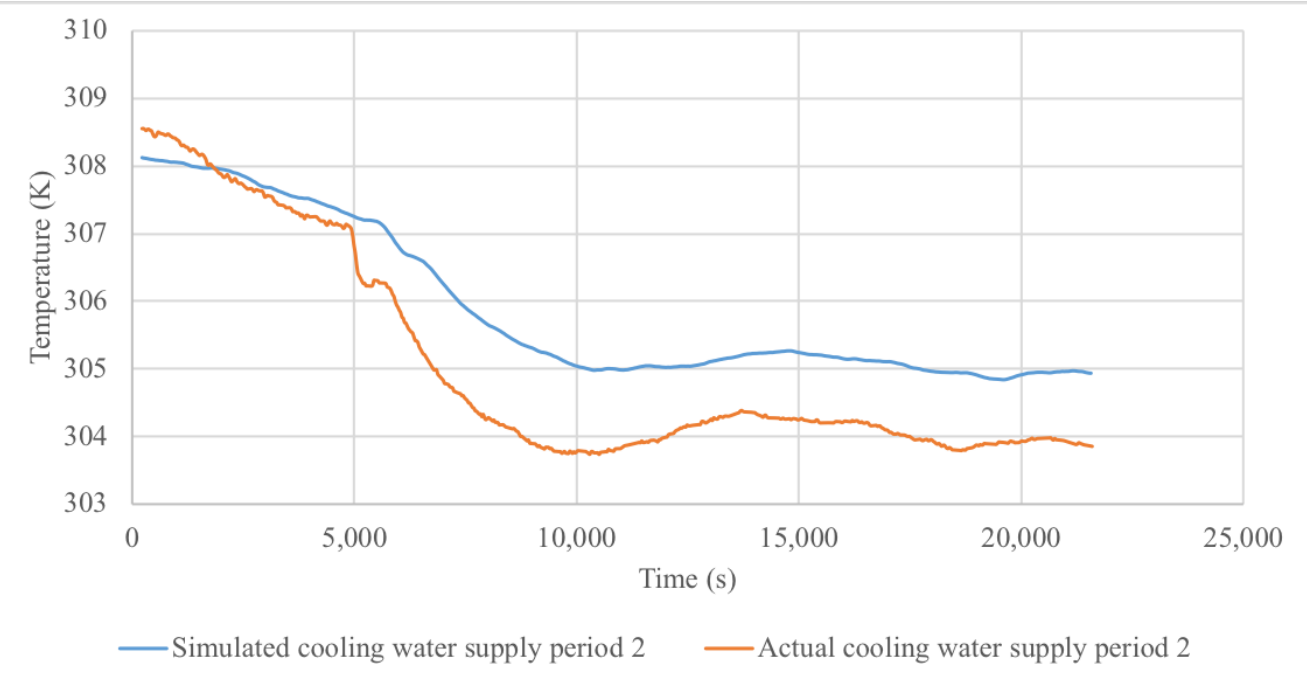

Figure 7: Cooling water supply temperature $\left(T_{C W S}\right)$ simulation vs. actual for period 2.

ment. The 123 smaller exchangers were combined into a single $11^{\text {th }}$ exchanger in order to simplify the model (see Table 7 ). In [3], the flow rate to each exchanger was measured by an electromagnetic flow meter, and this data was used to validate the model that was developed. The same approach is taken in this paper: Measured flow rates to the individual heat exchangers are not available, so an electromagnetic flow meter was used to measure flow rates by hand. These measurements were used to calculate the ratios between flows to each exchanger, and the total measured flow rates were scaled accordingly to determine the $\mathrm{CW}$ flow to each exchanger. These flow rates were used to fit the $k_{H X_{2}}$ hydraulic coefficients on the cooling water side of each exchanger. For the exchangers where hydrocarbon inlet and outlet stream temperatures and flow rates are historised, the $U$ value was fitted for each exchanger using the applicable hydrocarbon heat capacity values. Heat exchanger heat exchange surface area values (A in Table 1 ) were obtained from the data sheets of each exchanger. The dynamic temperature time constant for the hydrocarbon side was also fitted where temperatures are historised (see Table 6). The $\mathrm{R}^{2}$ coef- 
ficient of determination for each heat exchanger fit is also included in Table 6 . For exchangers where historised measured data were not available, datasheet information was used (see Table 7).

Table 6: Heat exchanger parameters fitted to design, and more complete plant data.

\begin{tabular}{|l|l|l|l|l|l|}
\hline Exchanger & $\begin{array}{l}\text { UA de- } \\
\text { sign }\end{array}$ & $\begin{array}{l}\text { UA fit- } \\
\text { ted }\end{array}$ & $\begin{array}{l}\tau_{T_{H X 1}} \text { fit- } \\
\text { ted }\end{array}$ & $\begin{array}{l}k_{H_{2}} \text { fit- } \\
\text { ted }\end{array}$ & $R^{2}$ of fit \\
\hline HX-06 & 226,233 & $187,535.3$ & 269.65 & 2.06 & 0.99 \\
\hline HX-07 & 125,457 & 75,624 & 208.64 & 0.97 & 0.99 \\
\hline HX-04 & 534,570 & 535,954 & 216 & 8.91 & 0.96 \\
\hline HX-09 & NA & 535,287 & 81.136 & 12.96 & 0.99 \\
\hline HX-05 & 81,760 & 35,928 & 538.1 & 4.99 & 0.23 \\
\hline
\end{tabular}

Table 7: Heat exchanger parameters fitted to design, and limited plant data.

\begin{tabular}{|l|l|l|}
\hline Exchanger & $\begin{array}{l}\text { UA de- } \\
\text { sign }\end{array}$ & $\begin{array}{l}k_{H X_{2}} \text { fit- } \\
\text { ted }\end{array}$ \\
\hline HX-01 & 142,639 & 10.95 \\
\hline HX-02 & 142,639 & 13.10 \\
\hline HX-03 & 533,096 & 5.01 \\
\hline HX-08 & $301,030.1$ & 11.25 \\
\hline HX-10 & $149,693.4$ & 26.93 \\
\hline $11^{\text {th }} H X$ & $514,076.2$ & 79.17 \\
\hline
\end{tabular}

Simulated and actual process temperatures for the exchangers where hydrocarbon temperatures and flow rates are measured, are shown in Figures 8 to 11. Actual and simulated data are compared for between 10 and 24 hours per exchanger. The models for exchangers HX-06, HX-07, HX-04 and HX-09 follow the actual data very closely (within 0.5 degree Kelvin over the operating envelope shown). For exchanger HX-05 there is an error of 1.3 degree Kelvin in the worst case. This difference is due to an unmeasured disturbance in the data, 


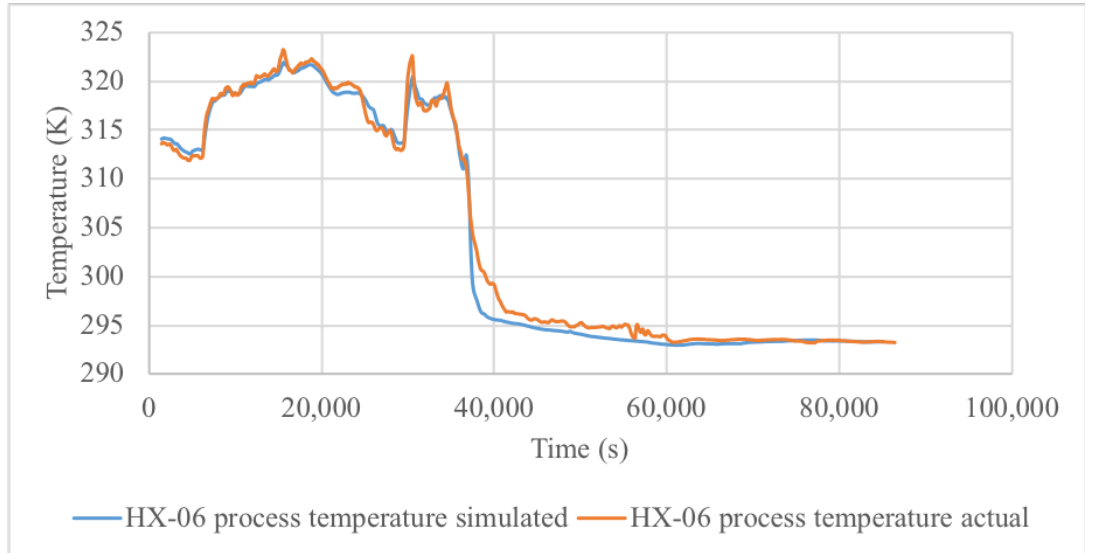

Figure 8: HX-06 process outlet temperature $\left(T_{H X 06}\right)$ simulated and actual data.

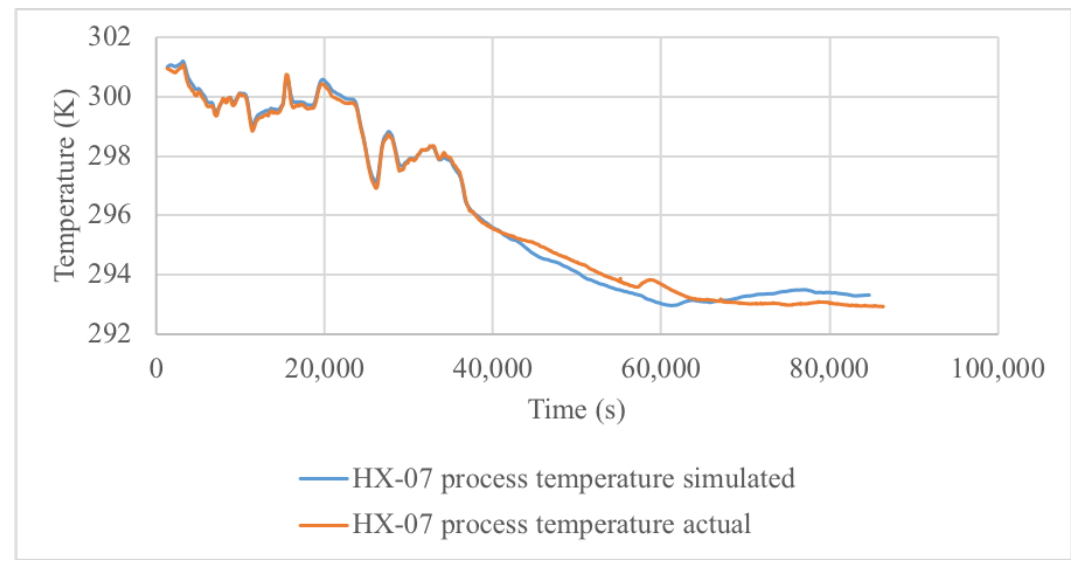

Figure 9: HX-07 process outlet temperature $\left(T_{H X 07}\right)$ simulated and actual data.

but is considered accurate enough for the purposes of this paper.

\section{Simulation}

In this section, the models developed in Sections 3 and 4 are simulated to observe the response of the model outputs to steps in the model inputs. With a view to future work where the model could be used for control and optimisation purposes, the most important measured model outputs are identified and called Controlled Varialbes (CVs). Input variables that can be readily actuated are 


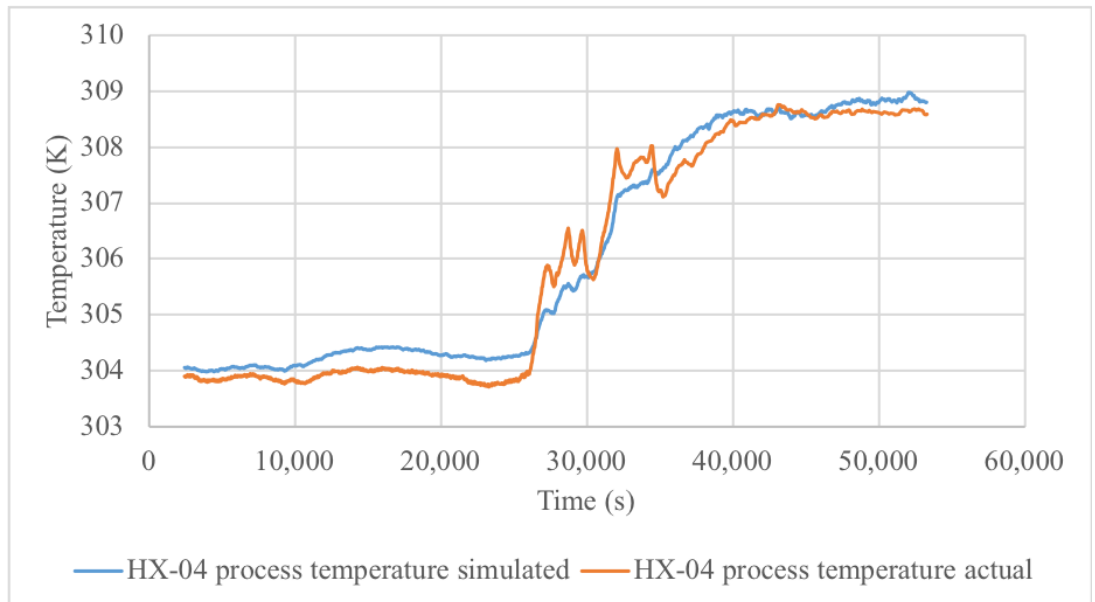

Figure 10: HX-04 process outlet temperature $\left(T_{H X 04}\right)$ simulated and actual data.

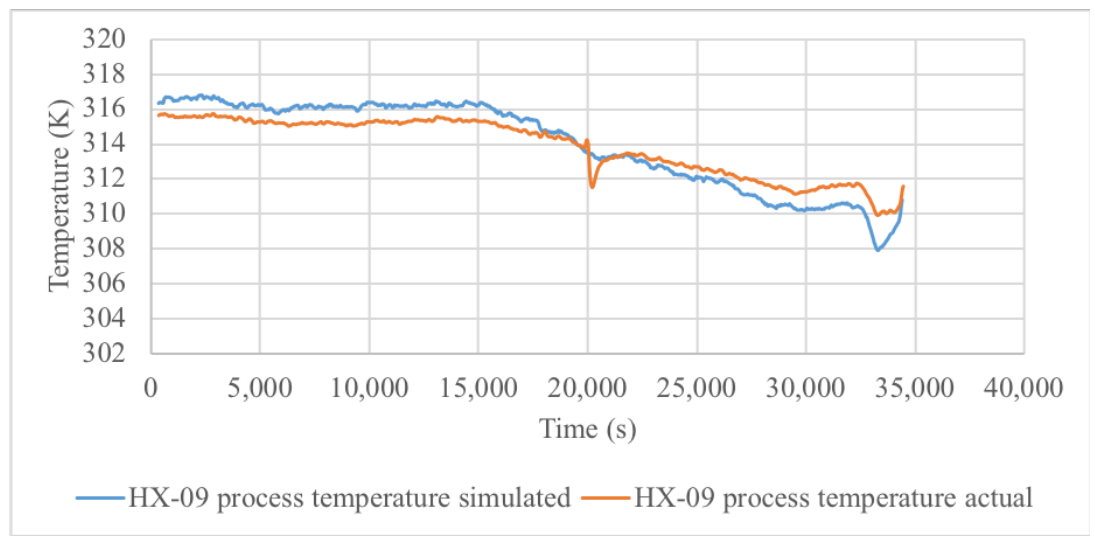

Figure 11: HX-09 process outlet temperature $\left(T_{H X 09}\right)$ simulated and actual data.

called Manipulated Variables (MVs), and the environment variables that are measured disturbances are called Disturbance Variables (DVs).

The MVs and DVs are stepped one at a time while the remaining model inputs are held constant. The model was simulated on an Intel Core i7 $2.5 \mathrm{GHz}$ machine, with 8 logical cores. The model was developed and implemented in Python and C\#. The model is run with a sampling period of 200 milliseconds. A high sampling frequency is needed due to the stiff nature of the cooling tower state space model (see Section 3.1) in order to ensure stability and convergence. 


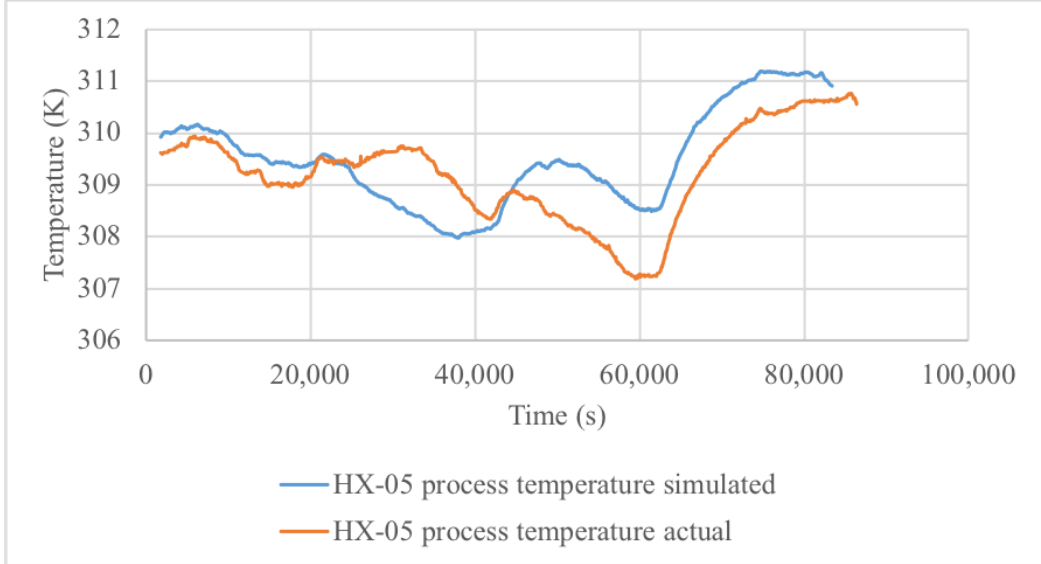

Figure 12: HX-05 process outlet temperature $\left(T_{H X 05}\right)$ simulated and actual data.

[44] shows that decreases in the $\mathrm{L} / \mathrm{G}$ ratio (Liquid to Gas ratio, in this paper water to air flow ratio) results in an increase in the efficiency of the cooling tower. The air flow in the model used in this paper, can be manipulated by changing the fan speed according to 10 . Four equal steps of 0.6 rps were made every 4 hours in the cooling water fan speed from 2.5 rps to 0.1 rps as shown in Figure 13. The resulting impact on cooling tower fan power is shown in Figure 14 . and the impact on process temperature outlet of HX-03, cooling water return temperature and cooling water supply temperature are shown in Figure 15 . The impact of the fan speed on the plant temperatures at the normal operating speed of $2 \mathrm{rps}$, is much less than when the speed moves to below $0.7 \mathrm{rps}$. This suggests that the plant could be optimised by running the fans at lower speed where less power is consumed.

Figure 16 shows the impact of steps in the DV ambient temperature on process temperature (HX-03; see Figure 1), cooling water return temperature, and the cooling water supply temperature. The step increases are simulated to occur every 4 hours, starting at 283 Kelvin and going up to 313 Kelvin. This DV impact is also reflected in the validation data in Figure 6

The 3 cooling tower fans were shut down one by one in a hybrid control fashion and the impact on the plant temperatures simulated (see Figure 17). The 


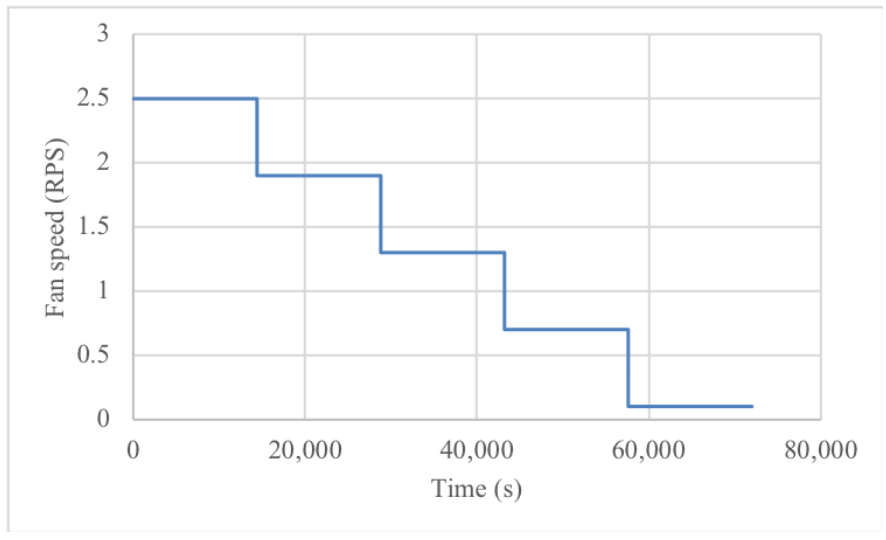

Figure 13: Cooling tower fan speed $(n)$ as stepped.

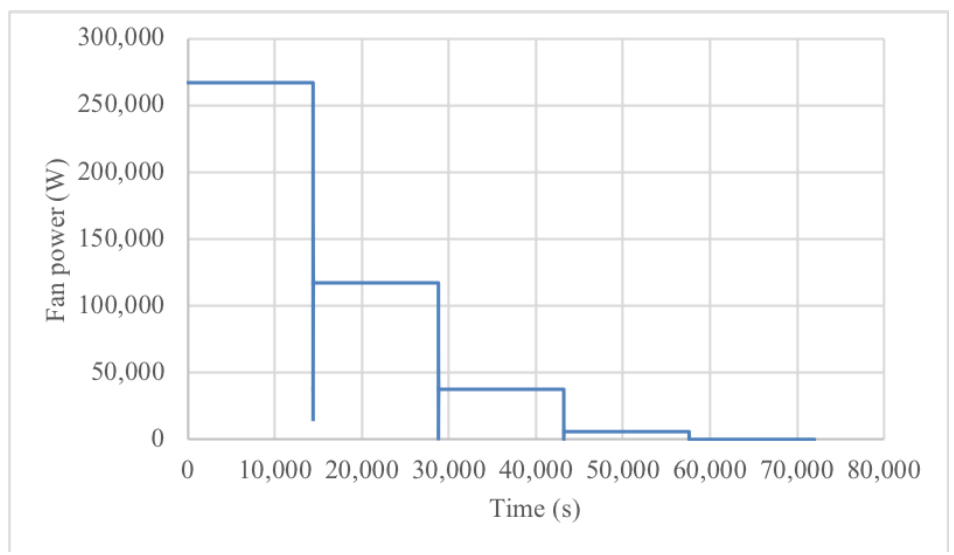

Figure 14: Cooling tower fan power $\left(P_{f}\right)$ response when speed stepped.

lack of cooling capacity with fewer towers available, increases non-linearly as the fraction of cooling capacity lost with each fan trip, increases. The settling time also increases non-linearly with the linear drop in cooling tower fans running, with the total cooling water network temperature dynamics becoming much slower as less fan draft is available.

The pump speed was stepped hourly from $10.33 \mathrm{rps}$ to $14.33 \mathrm{rps}$, and the response of the pump power, total flow through the circuit, and the plant temperatures were simulated (see Figure 18 to Figure 20). These limits were chosen to be within a window of $15 \%$ around the normal operating point of the pump 


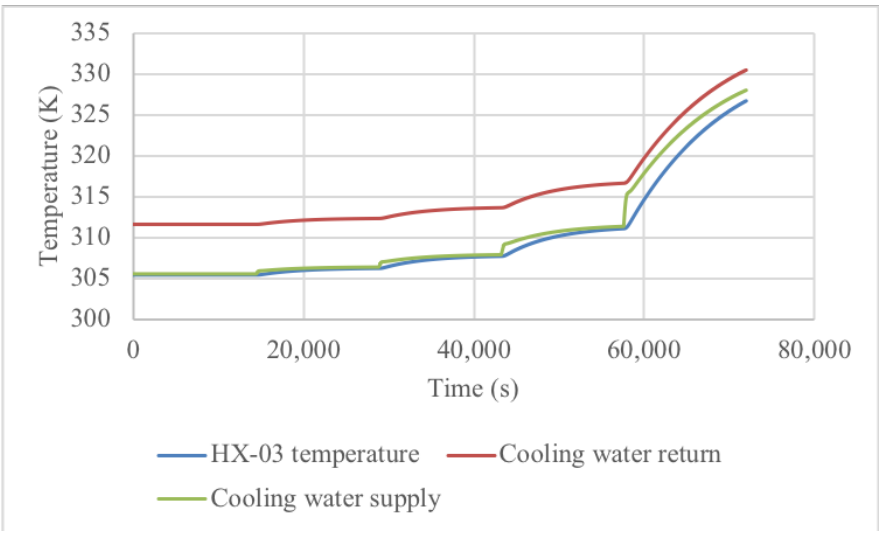

Figure 15: Plant model temperatures $\left(T_{H X 03}, T_{C W R}, T_{C W S}\right)$ response to stepped cooling tower fan speed.

speed. Larger steps in pump speed reduces the convergence robustness of the model. The non-linear nature of the pump power consumption to pump speed relationship is evident. Further, it can be seen from Figure 20 that the pump speed will be a viable MV along with the other MVs for control and optimisation purposes. Larger pump speeds result in higher heat transfer rates in the heat exchangers (depending on each heat exchanger's operating point) resulting in cooler hydro-carbon streams. In addition, it can be seen that larger flow rates and speeds result in incrementally less increase in heat exchange, than lower flow rates and pump speeds. This reflects the results from the cooling tower air fan speed and resulting air flow's incremental impact on cooling in the tower. At lower pump speeds the cooling water network temperatures are more sensitive.

The two running pumps were reduced to one running pump by tripping out one pump, and the resulting response of the total flow through the circuit, pump power, and plant temperatures are shown in Figure 21 and Figure 22. This is the natural extension of the pump speed simulations, where in this case the reduction in heat duty in the heat exchangers are more severe. This results in the pumps being turned into a potential hybrid control MV, just like the cooling tower fans, as an extension of its continuous MV control capability.

The ambient relative humidity DV was stepped down from $100 \%$ to $0 \%$ 


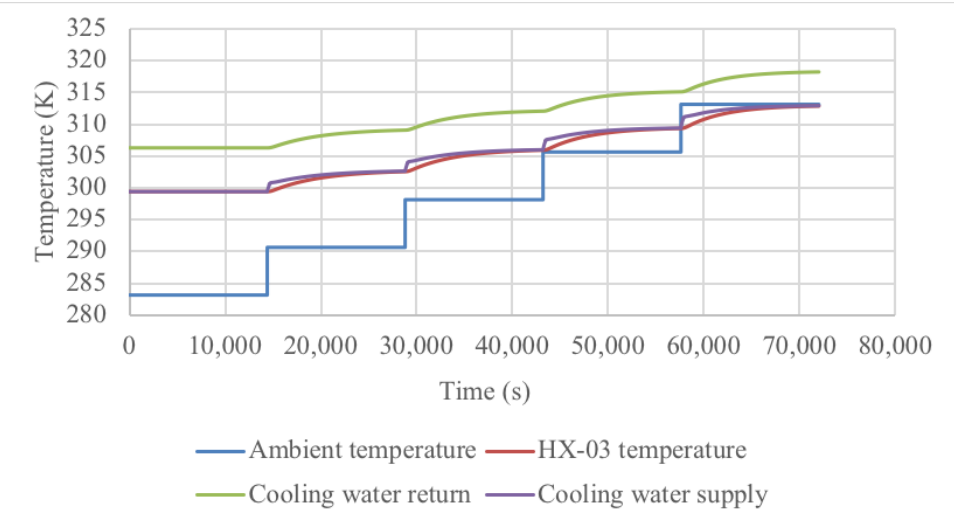

Figure 16: Ambient temperature $\left(T_{a_{i n}}\right)$ stepped and plant model temperatures $\left(T_{H X 03}\right.$, $\left.T_{C W R}, T_{C W S}\right)$ response.

every 4 hours (see Figure 23), and the effect of these changes on the response of plant temperatures are shown in Figure 24. At 100\% humidity the evaporative cooling in the cooling towers is at minimum, and it is at maximum for this DV at $0 \%$ humidity. The change in cooling in the process streams follows the drop in evaporation due to the ambient humidty. The loss of cooling water in the network due to the extra evaporation following the drops in humidity, is replaced with additional make-up water flow controlled by the PID level controller, as seen in Figure 23

The control valve MV controlling cooling water flow to the $2^{\text {nd }}$ heat exchanger (HX-02) was stepped from turn down (1\%) to 100\% open in 10 linear hourly steps, and the response of the valve flow, total circuit flow, another process temperature (HX-06 process temperature) and other plant temperatures are shown in Figure 25 to Figure 27. The linearisation achieved with the equal percentage characteristic is evident. Nevertheless, temperature controllability of the hydrocarbon stream of HX-02 is much greater, and quite effective, below $50 \%$ valve opening.

The impact on the rest of the system temperatures is much less, since only one valve was stepped. The HX-06 process temperature increases very slightly by a total of 0.3 Kelvin from $1 \%$ to $100 \%$ for the valve. The CW flow through 


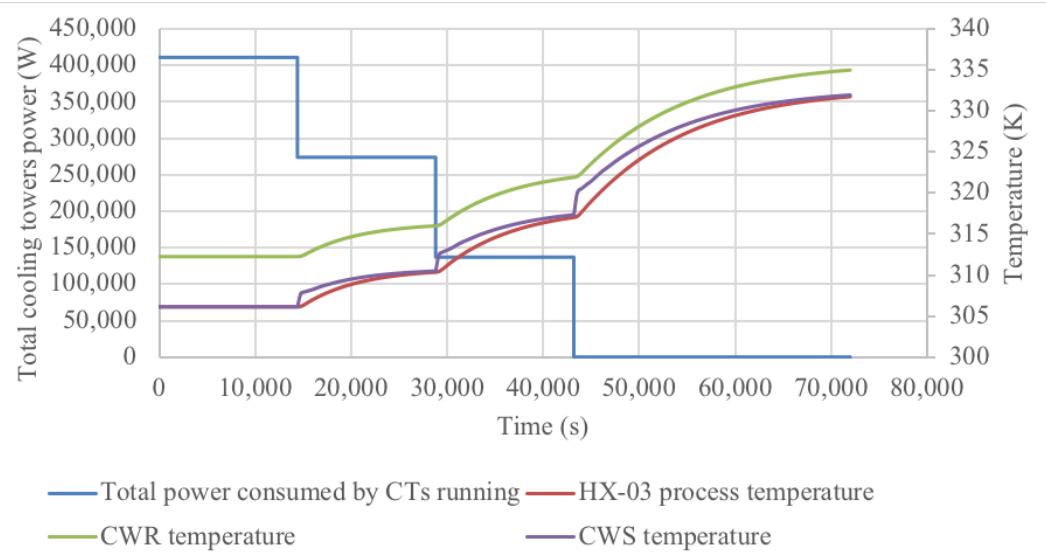

Figure 17: Cooling tower fans shut-down one-by-one and power response $\left(P_{f_{\text {total }}}\right)$ and subsequent plant model temperature $\left(T_{H X 03}, T_{C W R}, T_{C W S}\right)$ response.

HX-06 decreases by around $4 \%$ over the full stepping sequence, which partly explains the small drop in temperature for the outlet process flow of that exchanger.

The total flow through the circuit increases (Figure 26) with the valve being stepped open, since the total resistance of the circuit from the outlet of the pumps, is decreased with increased valve opening. Less pressure drop over the circuit results in the pumps moving down their operating curve towards higher flow.

\section{Discussion and Conclusion}

The plant exhibits strong non-linear and integrated hydraulic and thermodynamic behaviour. This is true of both steady-state process gains, and times to steady-state.

${ }_{640}$ There are significant differences in time to steady-state between some of the MVs and the CVs. In general the closer the MVs are to the hydrocarbon streams, the faster the process dynamics. Changes in the water side of the cooling tower (e.g. pump speed changes), affect the process temperatures significantly faster (1 hour time to steady-state) than air side changes (e.g. the 


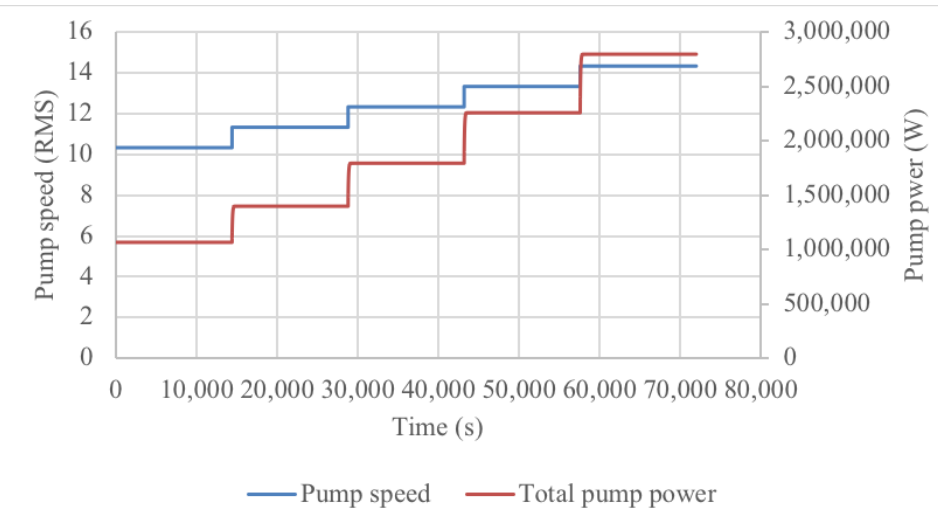

Figure 18: Pump speed $(\omega)$ stepped, and pump power $\left(P_{p}\right)$ response.

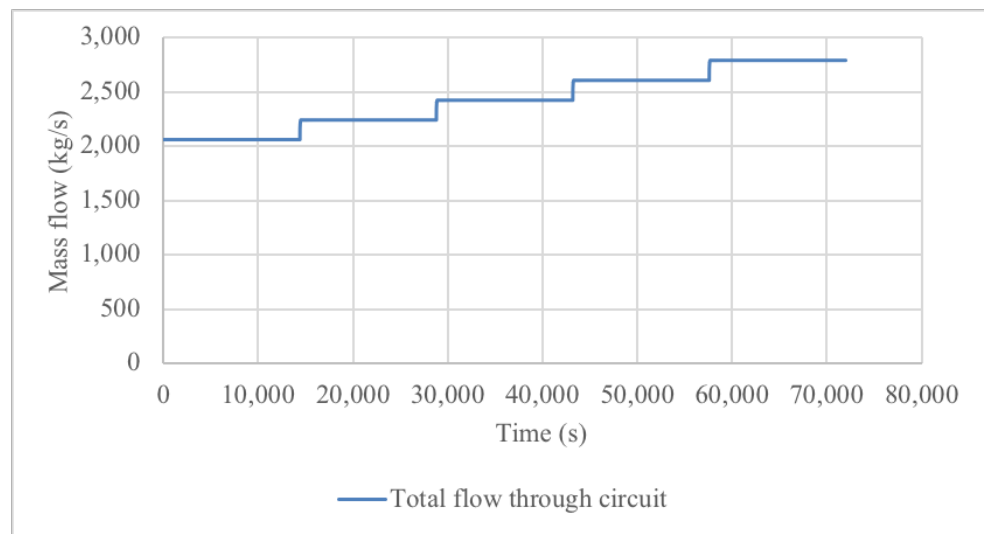

Figure 19: Total mass flow rate $\left(F_{C W S}\right)$ through circuit response to stepped pump speed $(\omega)$.

645 ambient humidity and ambient temperature, and the MV fan speed).

The simulation results in Section 6 show that a number of MVs can be used to control the process outlet temperatures of the heat exchangers. These MVs include the cooling tower fan speeds (Figure 15), the pump speed of the cooling water supply pumps (Figure 20, and the valve openings of the cooling water flow to each exchanger (Figure 27).

The integrated hydraulics of the plant is seen in the dynamic transients when the mass flow of the circuit is changed (e.g. Figure 19 and Figure 26). The non- 


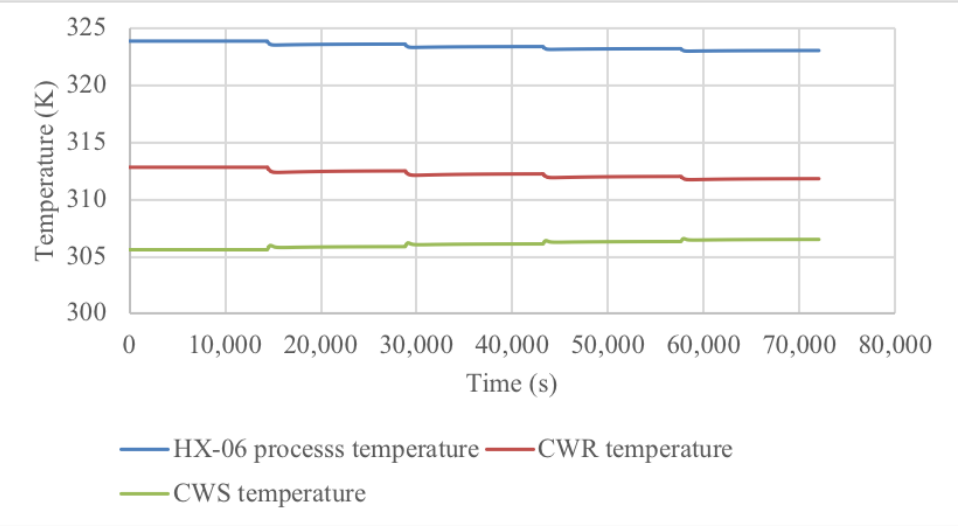

Figure 20: Plant model temperatures $\left(T_{H X 06}, T_{C W R}, T_{C W S}\right)$ response to stepped pump speed $(\omega)$.

linear nature of the installed hydraulic characteristic of the cooling water flow valve to each exchanger is seen in Figure 25. The power consumed by the rotating equipment in the circuit exhibits a non-linear relationship with respect to plant state variables, especially fan power with respect to speed (Figure 14). The plant temperatures also exhibit a non-linear relationship with the cooling tower on-off status as shown in Figure 17.

There exists an opportunity to minimise power consumption (see e.g. [45]), and control process temperature by utilising some or all of the manipulated variables. For this purpose, an Advanced Process Control (APC) scheme could be utilised (see e.g. [46]).

The main DVs studied in the work, are the ambient temperature and humidity (Figure 16 and Figure 24), as well as the hydro-carbon mass flow rates and hydrocarbon input temperatures to the heat exchangers. The control scheme that will utilise the model developed in this work, could be used to reject these disturbances.

The overall model developed and simulated in this paper is aimed at a specific process layout (Figure 1). However, the developed models are for unit operations, which have been linked in a modular fashion through the hydraulic modelling performed and fitted to the plant modelled. The developed models 


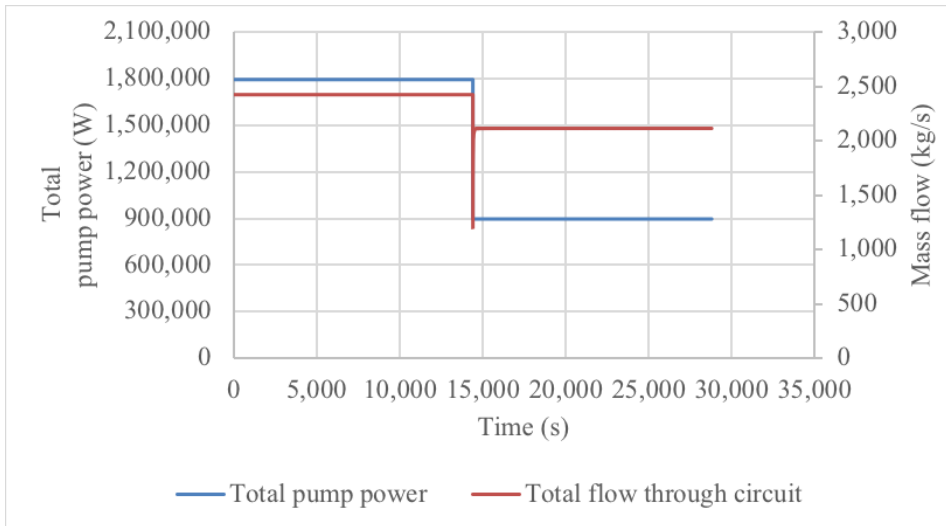

Figure 21: One of the two pumps tripped power response $\left(P_{p}\right)$, and subsequent total flow through circuit $\left(F_{C W S}\right)$ response.

can also be used for a different process layout, when fitted to relevant data and linked through the appropriately configured hydraulic models.

A first principles dynamic model augmented with Hammerstein models, as constructed in this paper is also very useful in order to analyse the performance of the actual plant, identify steady-state deviations from design early, online dynamic early event detection, as well as in operator training.

\section{Acknowledgements}

The authors would like to thank ORYX GTL for making plant data available for this research. This work is based on research supported in part by the National Research Foundation of South Africa (Grant Number 90533).

\section{References}

[1] C. J. Muller, I. K. Craig, Modelling of a dual circuit induced draft cooling water system for control and optimisation purposes, Journal of Process Control 25 (2015) 105-114.

[2] M. M. Castro, T. W. Song, J. M. Pinto, Minimization of operational costs 


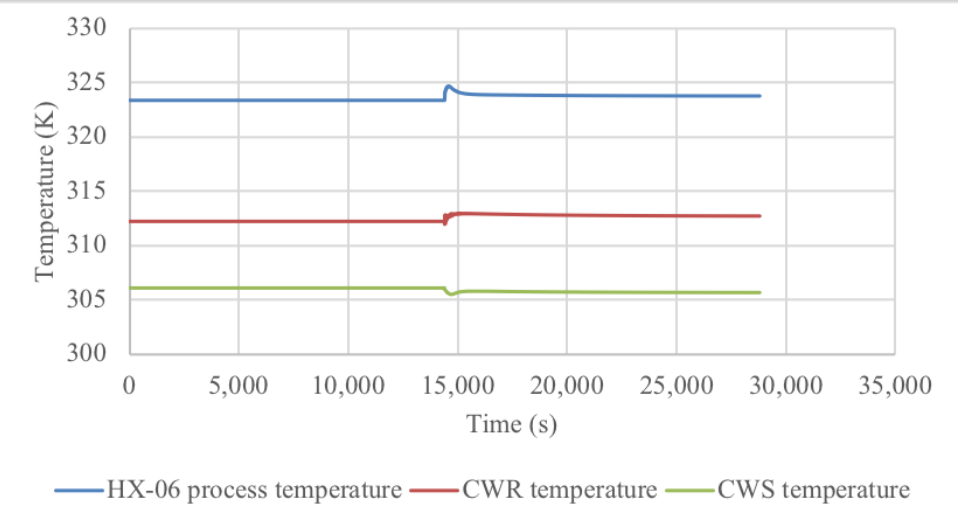

Figure 22: Plant model temperatures $\left(T_{H X 06}, T_{C W R}, T_{C W S}\right)$ response to one pump tripped scenario.

in cooling water systems, Transactions of the Institution of Chemical Engineers 78 (2000) 192-201.

[3] G. F. Cortinovis, M. T. Ribeiro, J. L. Paiva, T. W. Song, J. M. Pinto, Integrated analysis of cooling water systems: Modeling and experimental validation, Applied Thermal Engineering 29 (2009) 3124-3131.

[4] P. Malinowski, M. Sulowicz, J. Bujak, Neural model for forecasting temperature in a distribution network of cooling water supplied to systems producing petroleum products, International Journal of Refrigeration 34 (2011) 968-979.

[5] E. Rubio-Castro, M. Serna-Gonzalez, J. M. Ponce-Ortega, M. M. ElHalwagi, Synthesis of cooling water systems with multiple cooling towers, Applied Thermal Engineering 50 (2013) 957-974.

700

[6] C. A. Floudas, Nonlinear and Mixed-Integer Optimization, Oxford University Press, New York, USA, 1995.

[7] J. C. Kloppers, D. G. Kröger, A critical investigation into the heat and mass transfer analysis of wet counter flow cooling towers, International Journal of Heat \& Mass Transfer 48 (2005) 765-777. 


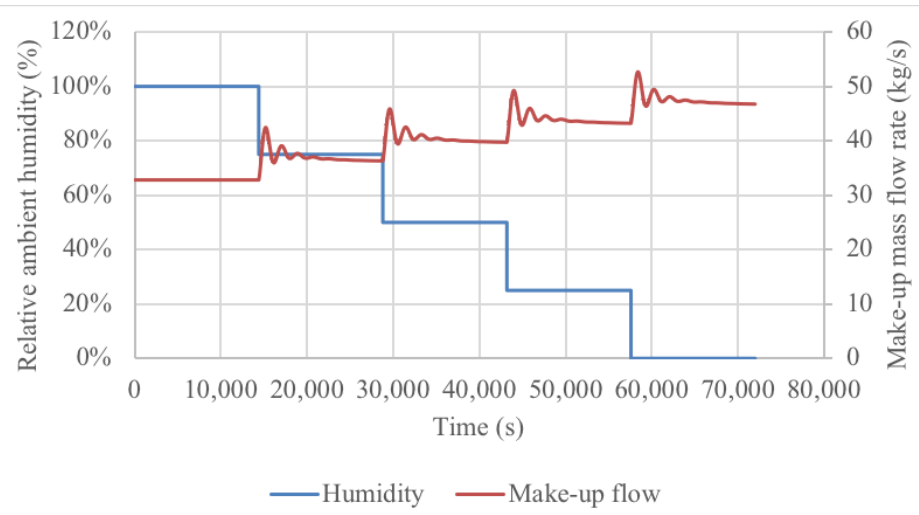

Figure 23: Ambient humidity $\left(Y_{a_{i n}}\right)$ steps and make-up flow $\left(F_{C W M U}\right)$ response.

[8] X. Li, Y. Li, Dynamic modeling of mechanical draft counter-flow wet cooling tower with modelica, in: Proceedings of the International Refridgeration and Air Conditioning Conference, Purdue University, West Lafayette, USA, 2010, pp. 2322-2330.

[9] A. Löfgren, Modeling and simulation of a cooling tower with extended uses (2015).

[10] W. L. McCabe, J. C. Smith, P. Harriott, Unit Operations of Chemical Engineering, 7th Edition, McGraw-Hill, New York, USA, 2005.

[11] D. Green, R. Perry, Perry's Chemical Engineers' Handbook, 8th Edition, McGraw-Hill, New York, USA, 2007.

[12] R. Stull, Wet-bulb temperature from relative humidity and air temperature, Journal of Applied Meteorology and Climatology 50 (2011) 2267-2269.

[13] S. P. Fisenko, A. A. Brin, A. I. Petruchik, Evaporative cooling of water in a mechanical draft cooling tower, International Journal of Heat and Mass Transfer 47 (2004) 165-177.

[14] C. A. X. Marques, C. H. Fontes, M. Embiruu, R. A. Kalid, Efficiency control in a commercial counter flow wet cooling tower, Energy Conversion and Management 50 (2009) 2843-2855. 


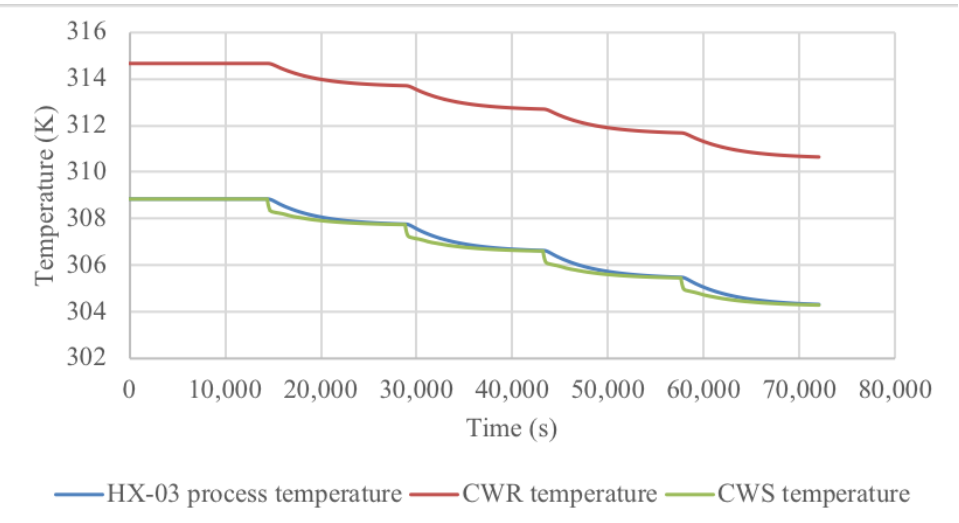

Figure 24: Plant model temperature $\left(T_{H X 03}, T_{C W R}, T_{C W S}\right)$ response to ambient humidity $\left(Y_{a_{i n}}\right)$ steps.

[15] M. Picon-Nunez, G. T. Polley, L. Canizalez-Davalos, E. K. Tamakloe, Design of coolers for use in an existing cooling water network, Applied Thermal Engineering 43 (2012) 51-59.

[16] J. M. Ponce-Ortegaa, M. Serna-Gonzalez, A. J. Gutierrez, Optimization model for re-circulating cooling water systems, Computers and Chemical Engineering 34 (2010) 177-195.

[17] M. A. Al-Nimr, Dynamic thermal behaviour of cooling towers, Energy Conversion Management 39 (1998) 631-636.

[18] Z. Ma, S. Wang, F. Xiao, Online performance evaluation of alternative control strategies for building cooling water systems prior to in situ implementation, Applied Energy 86 (2008) 712-721.

[19] F. Alnaimat, J. F. Klausner, R. Mei, Transient analysis of direct contact evaporation and condensation within packed beds, International Journal of Heat and Mass Transfer 54 (2011) 3381-3393.

[20] M. Nasrabadi, D. P. Finn, Mathematical modeling of a low temperature low approach direct cooling tower, Applied Thermal Engineering 64 (2014) 273-282. 


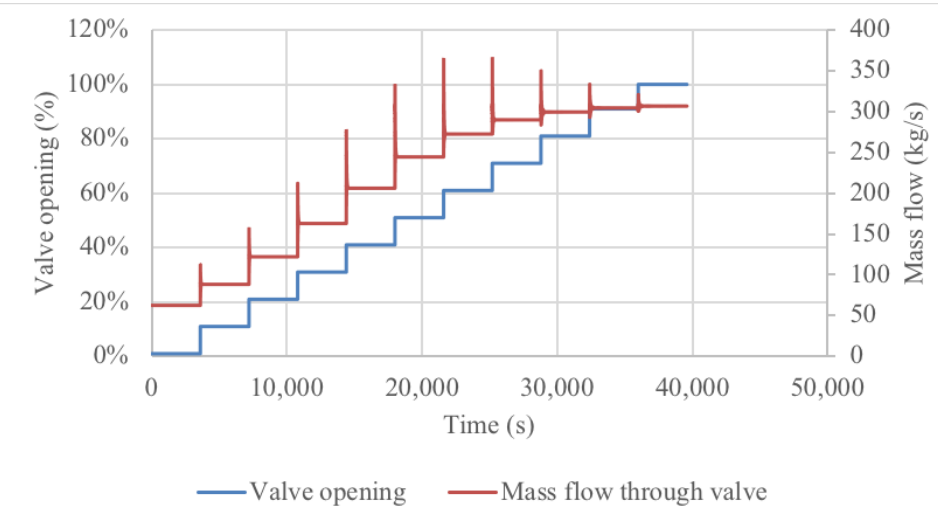

Figure 25: CW flow valve $\left(V_{O P}\right)$ to one exchanger stepped, and mass flow through valve $(F)$ response.

[21] S. Middleman, An Introduction to Mass and Heat Transfer - Principles of Analysis and Design, John Wiley \& Sons, New York, USA, 1998.

[22] J. C. Kloppers, D. G. Kröger, The Lewis factor and its influence on the performance prediction of wet-cooling towers, International Journal of Thermal Sciences 44 (2005) 879-884.

[23] Y. Huang, K. Zhang, S. Yang, Y. Jin, A method to measure humidity based on dry-bulb and wet bulb temperatures, Research Journal of Applied Sciences, Engineering and Technology 6 (16) (2013) 2984-2987.

[24] W. K. Lewis, The evaporation of a liquid into a gas, Trans. ASME 44 (1922) 325-340.

[25] M. Vaccarini, A. Carbonari, M. Casals, Development and calibration of a model for the dynamic simulation of fans with induction motors, Applied Thermal Engineering 111 (2017) 647-659.

[26] E. Al-Bassam, R. Alasseri, Measurable energy savings of installing variable frequency drives for cooling towers fans, compared to dual speed motors, Energy and Buildings 67 (2013) 261-266. 


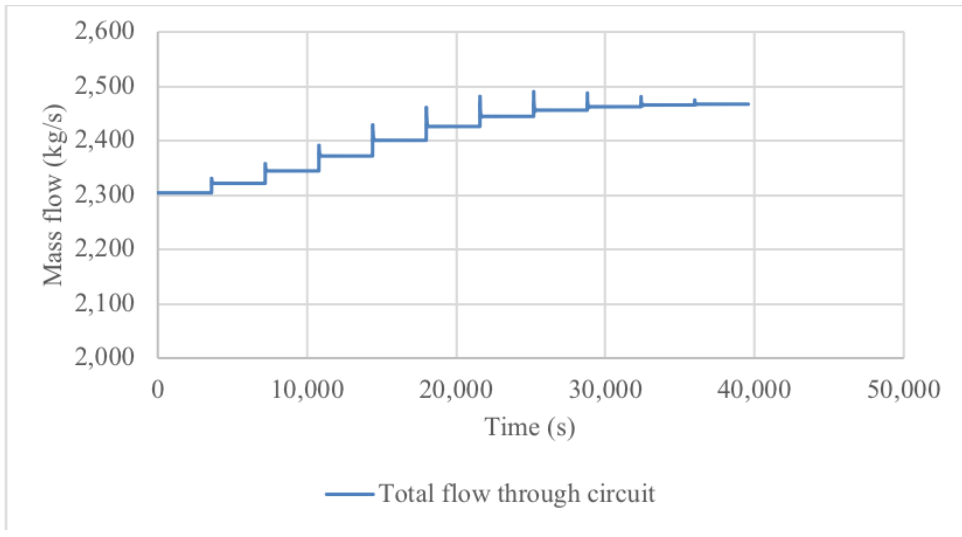

Figure 26: Total mass flow through $\mathrm{CW}$ circuit $\left(F_{C W R}\right)$ response to $\mathrm{CW}$ exchanger flow valve $\left(V_{O P}\right)$ steps.

[27] R. Saidur, S. Mekhilef, M. B. Ali, A. Safari, H. A. Mohammed, Applications of variable speed drive (VSD) in electrical motors energy savings, Renewable and Sustainable Energy Reviews 16 (2012) 543-550.

[28] P. C. Sen, Principles of Electric Machines and Power Electronics, John Wiley and Sons, USA, 1997.

[29] J. Szymczyk, K. Karaskiewicz, The modeling of centrifugal pump transients, Transaction of the Institute of Fluid Flow Machinery - Polish Academy of Sciences 130 (2015) 83-92.

[30] Q. C. Y. Wang, A direct optimal control strategy of variable speed pumps in heat exchanger networks and experimental validations, Energy 85 (2015) 609-619.

[31] J. Sun, X. Feng, Y. Wang, Cooling-water system optimisation with a novel two-step sequential method, Applied Thermal Engineering (2015) 1-8.

[32] D. E. Seborg, T. F. Edgar, D. A. Mellichamp, F. J. Doyle, Process Dynamics and Control, 4th Edition, John Wiley and Sons, Danvers, MA, USA, 2016. 


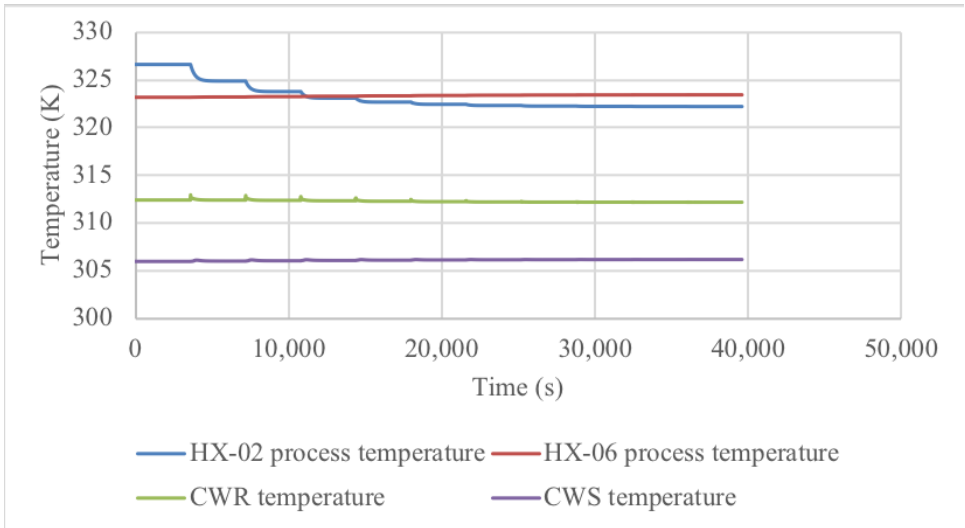

Figure 27: Plant model temperature $\left(T_{H X 02}, T_{H X 06}, T_{C W R}, T_{C W S}\right)$ response to CW flow to exchanger valve $\left(V_{O P}\right)$ steps.

[33] J. R. Eliot, C. T. Lira, Introductory Chemical Engineering Thermodynamics, 2nd Edition, Prentice-Hall, Upper Saddle River, New Jersey, USA, 2012.

[34] T. Gao, B. G. Sammakia, B. T. Murray, A. Ortega, R. Schmidt, Cross flow heat exchanger modeling of transient temperature input conditions, IEEE transactions on components, packaging and manufacturing technology 4 (11) (2014) 1796-1807.

[35] M. Bakosova, J. Oravec, Robust model predictive control for heat exchanger network, Applied Thermal Engineering 73 (2014) 924-930.

[36] W. Ramirez, Computational Methods for Process Simulation, 2nd Edition, Butterworth-Heineman, Oxford, UK, 1997.

[37] C. H. Edwards, D. E. Penney, Elementary Differential Equations with Boundary Value Problems, Prentice-Hall, New Jersey, USA, 1993.

[38] S. M. Safdarnejad, J. R. Gallacher, J. D. Hedengren, Dynamic parameter estimation and optimization for batch distillation, Computers \& Chemical Engineering 86 (2016) 18-32. 
[39] K. Dai, N. Wang, A hybrid DNA based genetic algorithm for parameter estimation of dynamic systems, Chemical Engineering Research and Design 90 (2012) 2235-2246.

[40] J. Kennedy, R. C. Eberhart, Particle swarm optimization, in: Proceedings of the 1995 IEEE International Conference on Neural Networks, IEEE, Perth, Australia, 1995, pp. 1942-1948.

[41] J. Kennedy, R. C. Eberhart, A discrete binary version of the particle swarm algorithm, in: Proceedings of the 1997 IEEE International Conference on Computational Cybernetics and Simulation, IEEE, Orlando, USA, 1997, pp. 4104-4108.

[42] M. Clerc, Particle Swarm Optimisation, ISTE Ltd, London, UK, 2006.

[43] Q. B. Jin, Z. J. Cheng, J. Dou, L. T. Cao, K. W. Wang, A novel closed loop identification method and its application of multivariable system, Journal of Process Control 22 (2012) 132-144.

[44] S. Bedekar, P. Nithiarasu, K. Seetharamu, Experimental investigation of the performance of a counter-flow packed-bed mechanical cooling tower, Energy 23 (11) (1998) 943-947.

[45] C. J. Muller, I. K. Craig, Energy reduction for a dual circuit cooling water system using advanced regulatory control, Applied Energy 171 (2016) 287295. doi:10.1016/j.apenergy .2016.03.069.

[46] C. J. Muller, I. K. Craig, Economic hybrid non-linear model predictive control of a dual circuit induced draft cooling water system, Journal of Process Control 53 (2017) 37-45.

doi:http://dx.doi.org/10.1017/j. jprocont.2017.02.009. 